\title{
Model of PAH and PCB Bioaccumulation in Mya arenaria and Application for Site Assessment in Conjunction with Sediment Quality Screening
}

Criteria

by

Rachel H. Levine

B.A., Earth and Environmental Science

Wesleyan University, 1996

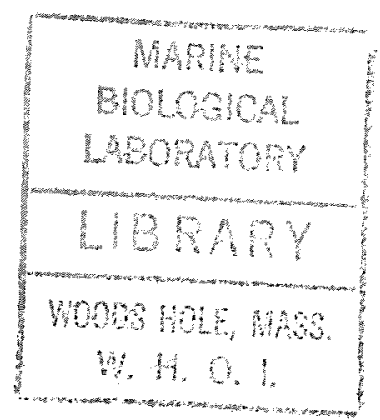

SUBMITTED TO THE DEPARTMENT OF OCEAN ENGINEERING IN PARTIAL FULFILLMENT OF THE REQUIREMENTS FOR THE DEGREE OF

MASTER OF ENGINEERING IN OCEAN ENGINEERING

at the

MASSACHUSETTS INSTITUTE OF TECHNOLOGY

and the

WOODS HOLE OCEANOGRAPHIC INSTITUTION

June 1999

- Rachel H. Levine. All rights reserved.

The author hereby grants to MTT permission to reproduce and to distribute publicly paper and electronic copies of this thesis document in whole or in part.

Signature of Author:

Department of Ocean Engineering May 21, 1999

Certified by:

Dr. Judith McDowell Senior Scientist, Biology Department, WHOI Thesis Supervisor

Certified by

$$
\begin{array}{r}
\text { Dr. Judith Pederson } \\
\text { Manager, MITSG Center for Coastal Resources } \\
\text { Thesis Supervisor }
\end{array}
$$

Accepted by:

Professor Michael Triantafyllou Chairman, Joint Committee for Applied Ocean Science and Engineering, MIT/WHOI 


\title{
Model of PAH and PCB Bioaccumulation in Mya arenaria and Application for Site Assessment in Conjunction with Sediment Quality Screening Criteria
}

\author{
by \\ Rachel H. Levine \\ Submitted to the Department of Ocean Engineering on May 21, 1999 \\ in Partial Fulfillment of the Requirements for the Degree of Master of \\ Engineering in Ocean Engineering
}

\begin{abstract}
A review of six methods for deriving sediment quality criteria (SQC) was conducted. Each approach was analyzed according to cost, difficulty, applicability and reliability. Results of this analysis led to the recommendation that the state of Massachusetts should use a combination of the Equilibrium Partitioning modeling approach and the Threshold Effects Level/Probable Effects Level correlative approach to SQC derivation. Criteria should then be applied as screening values for evaluation of sediment toxicity.
\end{abstract}

One significant component of sediment quality that all criteria approaches lack is the bioaccumulation/biomagnification of contaminants. Nor are there accurate, easily implemented models for benthically-coupled organisms such as Mya arenaria. In this document a bioaccumulation model for PAHs and PCBs was developed. The model considers contaminant partitioning into organism lipid and protein and incorporates organism exposure to contaminants through sediment and ingestion of contaminated food particles. Results show the model predicts PCB accumulation in M. arenaria with only a slight variation from observed data. Partitioning into sedimentary soot fraction was added to the model for PAHs. Results showed an increase in model accuracy, but predicted concentrations still remain greater than observed concentrations.

A combination of sediment quality criteria used as screening criteria and the bioaccumulation model for M. arenaria will improve the accuracy of site assessment of PAH and PCB compounds.

Thesis Supervisor: Dr. Judith McDowell

Senior Scientist, Biology Department, WHOI

Thesis Supervisor: Dr. Judith Pederson

Manger, MITSG Center for Coastal Resources 


\section{Acknowledgements}

There are a few amazing people who deserve my boundless thanks; without them this thesis would not have been possible.

To Dr. Judy McDowell, thank you for your insight and guidance and your confidence in my abilities. To Dr. Judy Pederson and Professor Phil Gschwend, thank you for your inspiring intensity and commitment and for stretching my mind in new (albeit sometimes painful) directions. To Professor Judy Kildow, thank you for always finding time to answer my questions.

Thank you to my family, who gave me the skills and the confidence to accomplish great things; without you I would not be where I am today. To my friends, thank you for the continuous moral support despite all the unreturned phone calls. And to Chris, thank you for your unwavering faith in me amidst all the blood, sweat and tears; I would not have made it through all those long nights without you. 


\section{Table of Contents}

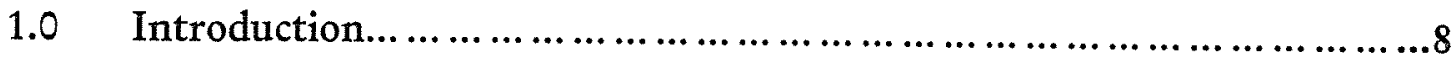

2.0 Sediment Quality Criteria: Relevance, History and Current Status.......12

2.1 SQC: Purpose.................................................................... 13

2.2 SQC: Original Development....................................................... 15

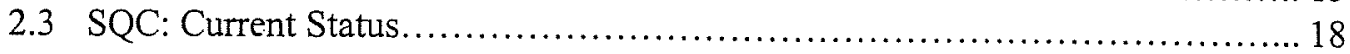

3.0 Approaches to Sediment Quality Criteria Development................. 22

3.1 Water Quality Criteria Approach................................................ 23

3.2 Spiked Sediment Toxicity Approach............................................ 25

3.3 Apparent Effects Threshold Approach.......................................... 27

3.4 Equilibrium Partitioning Approach............................................ 30

3.5 Effects Range-Low and Effects Range Median Approach....................... 35

3.6 Threshold Effects Level and Probable Effects Level Approach.................... 38

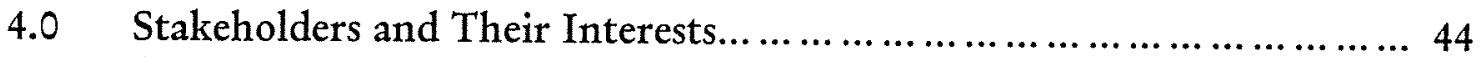

4.1 The US Environmental Protection Agency ......................................... 46

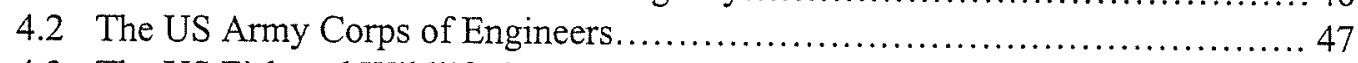

4.3 The US Fish and Wildlife Service and the National Oceanographic and Atmospheric Administration.................................................... 48

4.4 Massachusetts State Agencies.................................................. 49

4.5 Non-Governmental Organizations.............................................. 51

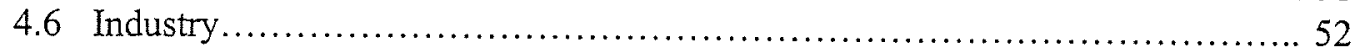

5.0 Conflicting Issues in SQC Development and Application..................53

6.0 Appropriate Guidelines for Massachusetts Marine Sediment...............56

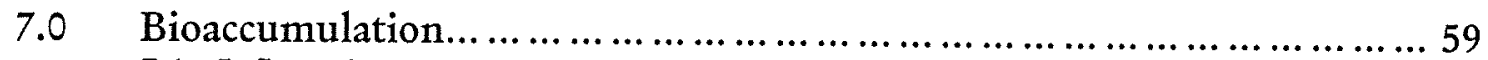

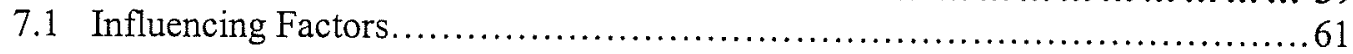

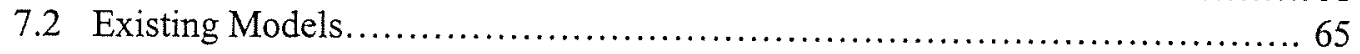

7.3 Creation of a New Bioaccumulation Mode1.................................... 70

8.0 Materials and Methods................................................... 77

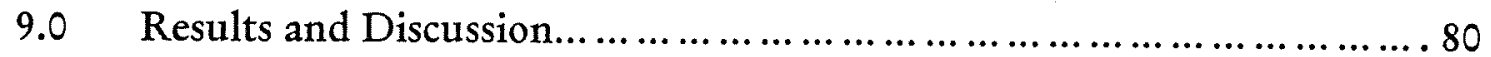

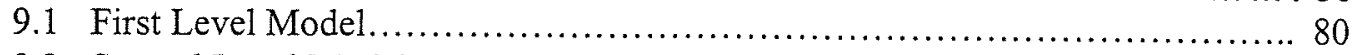

9.2 Second Level Model........................................................... 83

9.3 Third Level Model............................................................. 86

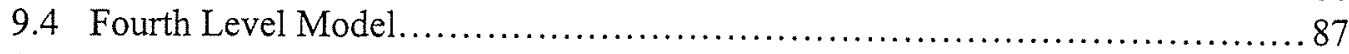

9.5 Summary of Methods, Models, Assumptions and Results........................ 91

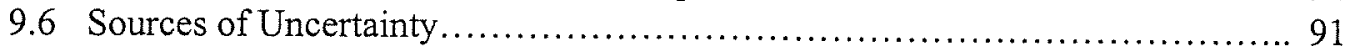

10.0 Conclusions and Future Recommendations... .........................95

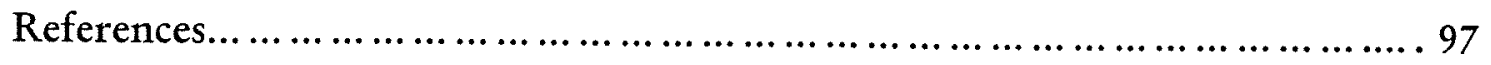

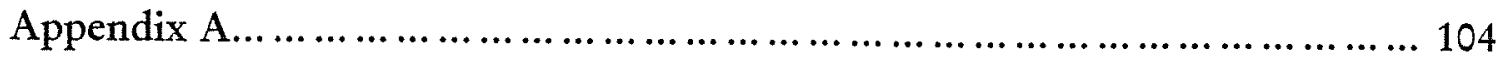




\section{List of Tables}

Table 1. Advantages and Disadvantages of National/Regional versus Site-specific Sediment Quality Criteria (USGS 1997)

Table 2. Summary of the Benefits and Limitations of Six Approaches to Sediment Quality Criteria Derivation

Table 3. Overall Rating of Four Attributes of Six Approaches to Sediment Quality Criteria Derivation

Table 4. Sediment (Column I) and clam (Column 2) PAH and PCB concentration data, sedimentary organic carbon fraction $\left(f_{o c}\right)$ and organism lipid fraction $\left(f_{\text {lipid }}\right)$ are given for each site (McDowell and Shea 1997). The results of testing the ACOE TBP model with the BSAF of 4 (USEPA and USACOE 1991) and the bivalvespecific BSAF (USACOE 1999) are listed in Columns III and IV respectively. Ratios of observed contaminant concentrations in clams to concentrations predicted by the TBP model were also calculated to determine the factor by which empirical concentrations were over- or underpredicted.

Table 5. Partition coefficients

Table 6. Biological partition coefficients calculated from First Level Model $\left(\mathrm{K}_{\text {bio-theoretical }}\right)$ (Column I) compared to empirical clam PAH and PCB concentration data $\left(\mathrm{K}_{\text {bio- }}\right.$ observed) (Column II) (McDowell and Shea 1997). Ratios of observed contaminant concentrations in clams versus concentrations predicted by the First Level model were also calculated to determine the factor by which empirical concentrations were over- or underpredicted.

Table 7. Biological partition coefficients calculated by Second Level $\left(\mathrm{K}_{\text {bio2-theoretical }}\right)$ and Third Level Model $\left(\mathrm{K}_{\text {bio3-theoretical }}\right)$ compared to empirical clam PAH and PCB concentration data $\left(\mathrm{K}_{\text {bio2-empirical }}\right)$ (McDowell and Shea 1997). Information used in these models and listed in this table includes the fraction of lipid per clam $\left(f_{\text {lipid }}\right)$ (McDowell and Shea 1997), the fraction of protein per clam $\left(f_{\text {protein }}\right)$ ( $\mathrm{McD}$ owell, personal communication) and the fraction of food-associated contaminants ( $f_{\text {foou }}$ ) (benzo[a]pyrene: Gunnarsson et al. 1996; PCB 153: Bjork and Gilek 1999). Ratios of observed contaminant concentrations in clams versus concentrations predicted by Second and Third Level Models were calculated to determine the factor by which empirical concentrations were overor underpredicted. 
Table 8. Biological partition coefficients calculated by Fourth Level Model $\left(\mathrm{K}_{\text {bio4theoretical }}\right)$ compared to empirical clam PAH concentration data $\left(\mathrm{K}_{\text {bio4-empirical }}\right)$ (McDowell and Shea 1997). The fraction of soot carbon $\left(f_{s c}\right)$ in the sediment is also listed per site (Gustafsson and Gschwend 1998).

Table 9. Summary of Bioaccumulation Modeling and Testing 


\section{List of Figures}

Figure 1. Diagram of the jurisdictions of various federal and state agencies involved in marine sediment quality.

Figure 2. Diagram of the relationship between bioaccumulation of contaminants from environmental media to organisms and biomagnification of effects from individual organisms to populations and eventually to the ecological community.

Figure 3. Physiologically based pharmacokinetic bioaccumulation model for Mya arenaria (Moreno et al. 1992).

Figure 4. Map of sample sites for sediment and clam data (McDowell and Shea 1997, above) and sedimentary soot carbon fractions (Gustafsson and Gschwend 1998, below).

Figure 5. Theoretical Bioaccumulation Potential model comparisons of predicted versus observed concentrations of PCBs in M. arenaria.

Figure 6. Theoretical Bioaccumulation Potential model comparisons of predicted versus observed concentrations of PAHs in $M$. arenaria.

Figure 7. Diagram of the environmental compartments that influence the concentration of nonpolar organic compounds in clams assuming equilibrium. The model is based on references and information as noted in the text. 


\subsection{Introduction}

With the advent of the industrial age, the use of chemicals in processes and products has risen exponentially. Correspondingly, the volume of toxic waste increased, creating new disposal issues and safety concerns. Until the last few decades, the oceans were perceived as a free dumping ground, an easily accessible common resource with unlimited capacity to dilute and transport waste. Following this logic, contaminants were discharged and dumped into rivers and coastal areas. Pollution accumulated from municipal (sewage treatment plants, CSOs), industrial (manufacturing plants, powergenerator operations), atmospheric and urban/rural sources (runoff from agricultural fields, landfills, toxic waste disposal sites, mining sites) (USEPA 1998b). Lack of adequate management, incomplete scientific information and the refusal of any individual or entity to take responsibility for ensuring the health of the oceans (Hardin 1968) led to the build-up of contaminant concentrations in the ocean ecosystem at potentially biologically harmful levels.

While the large volume of the oceans appeared to dissipate pollutants, natural fluxes and exchange processes eventually caused the contaminants to settle to the bottom. Because

of the hydrophobicity (tendency to partition out of water and dissolve into other types of compounds) and the ability of various chemicals to sorb to particulate matter, sediments especially accumulate high contaminant concentrations and are often considered the ultimate sink for pollutants (Salomons et al. 1987).

A classic example of polluted sediment and corresponding ecosystem contamination is Massachusetts Bay. For almost thirty years, the National Oceanic and Atmospheric Administration (NOAA) has cited Boston Harbor as one of the dirtiest harbors in the United States (NOAA 1985). Under current management plans, improved sewage treatment and construction of a new outfall pipe has decreased the impact of raw sewage 
and removal of sludge from harbor waters (MWRA 1997). The Clean Water Act of 1972 and enforcement by the US Environmental Protection Agency (EPA) of the National Pollution, Discharge and Elimination System (NPDES) limits on chemical dumping have reduced contaminant releases into Boston Harbor waters. There continue to be, however, multiple sources of pollutants to Boston Harbor and the rest of the Massachusetts Bay that have not adequately been addressed. Nonpolar organic pollutants and various metals are found in high enough concentrations in harbor sediments to be of concern. This document focuses on possible methods of predicting and therefore preventing effects on biota from high levels of the nonpolar organic compounds polycyclic aromatic hydrocarbons (PAHs) and polychlorinated biphenyls (PCB), which serve as typical examples of the problem.

The challenge for resource managers is to identify contaminant levels that, when exceeded, cause unacceptable biological effects. Over the years, many approaches to measuring sediment toxicity have been developed. The most widespread consistent use of sediment toxicity determinations is by the US Army Corps of Engineers (ACOE) and various state agencies. For example, sediment quality determinations are a required protocol in the Testing Manual for the Evaluation of Dredged Material Proposed for Ocean Disposal (USEPA and USACOE 1991). A tiered system of testing follows a flow chart of assessment options depending on whether test results do or do not meet certain standards. If the bulk chemistry of the sediment is greater than the acceptable range of toxicity, bioassay tests are required. These ranges, however, remain unofficial.

In an attempt to establish national guidelines to sediment quality for wide application by multiple users, the EPA and other technical experts reviewed all available methods for SQC derivation. The result of these studies was the EPA's proposal to use the equilibrium partitioning method $(\mathrm{EqP})$ for developing national sediment quality criteria (SQC) for three PAH compounds and two pesticides. Due to subsequent research and multiple public comments, however, a few years later the EPA rescinded its proposed $\mathrm{SQC}$ in order to conduct further testing. For example, the original assumption of one 
hundred percent bioavailability of contaminants in sediment is inaccurate if there are also soot particles present (McGroddy et al. 1996, McGroddy and Farrington 1995).

Currently, the national sediment quality criteria for nonpolar organic compounds are under development, but even though the EPA continues to endorse the EqP-derived values, the criteria are only recommendations. States are not obligated to follow them under law; only state-passed standards make clean-up levels official. Some coastal states such as Washington have adopted state SQC (WADEC 1991, Becker et al. 1989). Massachusetts, however, has not. In order to recommend the most appropriate set of SQC for Massachusetts, the methods of six approaches to SQC derivation were reviewed (there are over ten) and each approach analyzed in terms of cost, difficulty, applicability and reliability. These include: the water quality criteria approach, the spiked sediment toxicity approach, the apparent effects threshold approach, the equilibrium partitioning approach, the effects range-low and effects range-median approach and the threshold effects level and probable effects level approach. Relevant legislation and the interests of and conflicts between stakeholders are also analyzed.

One essential component that all SQC approaches lack is bioaccumulation: the accumulation in organism tissue of contaminants from the environment. The same hydrophobic properties that allow PAHs and PCBs to sorb to sediment particles also enable them to accumulate in various body components of organisms. Biota are usually exposed to chemicals through multiple routes. For example, filter feeders are benthicallycoupled organisms that both ingest chemicals sorbed to particulate matter and absorb them through direct contact with sediment and porewater. Continuous exposure to contaminants leads to an increase in body burden, which, at high enough levels, can adversely affect the individual organism. As contaminated organisms are consumed, chemicals are "passed on" to predators. Biomagnification occurs when organisms high in the food web accumulate concentrations of contaminants higher than in each individual food item. Eventually all levels of the food web are affected, including wildlife and human consumers. The effects on both wildlife and humans that can occur from eating 
seafood contaminated with PAHs and/or PCBs include birth defects, neurological disorders and organ diseases and malfunctions (USEPA 1998b). Individual effects also have the potential to multiply into population and community effects. This biomagnification occurs as too many organisms are adversely affected and can no longer function "properly" within the environment. Natural resource mangers need to be able to measure the health of the marine ecosystem in order to adequately protect ecosystem and public health.

Various models are available for predicting contaminant bioaccumulation. Model types include biota-sediment accumulation factors, the pharmacokinetic model and the hydrophobicity (equilibrium partitioning) model. These models are usually not both contaminant-specific and species-specific, but rather are designed for wide applicability. Most work in this area has been done on the mussel Mytilus edulis, but even other bivalves have a different degree of association with the sediment and therefore may respond differently to similar contamination scenarios. For example, currently there are no bioaccumulation models in use for Mya arenaria, a common bivalve species in many marine habitats. $M$. arenaria are benthically-coupled filter-feeders, an essential link in the marine food web. They are also good bioaccumulators of hydrophobic contaminants, making them a reliable indicator of ecosystem health.

In order to assist managers in assessing ecosystem health or evaluating the impact of proposed projects affecting the marine system, answers to the following questions are essential and are therefore examined in this document:

- How does observed bioaccumulation of PAHs and PCBs in Mya arenaria compare to predicted values?

- Can bioaccumulation of PCBs and PAHs in Mya arenaria be modeled accurately?

- Can bioaccumulation modeling be used in conjunction with sediment quality criteria for site assessment? 


\subsection{Sediment Quality Criteria: Relevance, History and Current Status}

In theory, sediment quality criteria are useful for multiple applications and are good indicators of ecosystem health. In practice, however, there are many caveats and inaccuracies to this type of toxicity assessment. There are two main reasons why, after decades of discussion and multiple iterations of this issue, no solution has yet been reached.

The first reason for the current lack of SQC is that there is no single approach that incorporates all aspects of the environment required to determine ecosystem health. SQC based on contaminant chemistry do not necessarily incorporate biological effects, providing results that are inaccurate for field situations. Variable analytical techniques may also affect the validity of results and prevent cross-comparisons between samples from different studies. For example, detection limits for some organic chemical are in the part per million range, which is not sensitive enough when correlating chemical concentrations with adverse effects on biota. Yet it is usually easier to determine chemical concentrations than biological effects, which has created a history of resistance to biological testing.

Aside from difficulty, there is another set of obstacles to application of biologicallyderived SQC. Results are often correlative rather than defining direct cause and effect relationships. For instance, the concentration of a contaminant in the field may yield a biological effect, but because sediments most often contain mixtures of contaminants, it is never certain which chemical has actually caused the adverse effects to biota. For this reason, contaminant concentration and biological effects are not necessarily related.

Another issue related to biologically-derived SQC is that although there are mixtures of contaminants evident in field sediment, criteria are developed for single contaminants. 
This eliminates the possibility of antagonistic or synergistic interactions between chemicals, which may directly affect the toxicity of the sediment. An approach to SQC development that incorporates both chemistry and biology would allow for the benefits of each while canceling out some of the limitations. As yet, no approach with this type of integration has been developed.

The second reason for the inability of the federal government and most of the state governments to implement sediment quality criteria is the lack of agreement between stakeholders. Federal and state government agencies, private industries and public organizations each have their own agendas and interests. Three main issues between involved parties are protective capability (liberal versus conservative), consistency (stateby-state versus national criteria) and cost (low versus high on the priority list). Because $\mathrm{SQC}$, even if published in the federal register by the EPA, will not be legally binding, there is no rush for consensus. This, coupled with the conflicts of interest between stakeholders and the limitations of chemically- and biologically-based approaches mentioned above has prevented this issue from being resolved.

In spite of these difficulties, however, site assessments are still occurring and sediment toxicity remains an important issue. Massachusetts is currently involved in the Boston Harbor Navigation Improvement Project, which requires testing of existing bottom sediment, resuspended sediment in the water column and the potential toxicity of dredged materials. Due to the lack of national SQC, the state must choose a set of SQC appropriate to its situation. The following sections (Sections 2-6) attempt to answer the question "What is the most viable approach to SQC for Massachusetts?"

\subsection{SQC: Purpose}

Sediment quality criteria reflect the use of available scientific data to assess the likelihood of significant adverse environmental effects to benthic organisms from sediment 
contamination. They are the basis for the derivation of regulatory requirements that will protect against these effects (USEPA 1993a). An adverse effect is defined as a statistically significant difference $(\mathrm{P} \leq 0.05)$ between study area conditions and conditions in an appropriate reference area (Becker et al. 1989). SQC can distinguish between three levels of contamination: sediments with contaminant concentrations a) lower than b) higher than, or c) near levels of advised contamination criteria (USEPA 1987).

Some managers state that if the adverse effects of sediment contamination are not also adversely affecting the beneficial uses of waterbodies (e.g. swimming), then government funds should not be used to develop SQC (Lee and Jones 1992). What these critics do not consider is the fact that while reproductive failure in benthic species due to high sediment contamination may not be directly related to recreation, indirect effects will eventually be evident. For example, if high levels of PCBs in the sediment bioaccumulate in benthic organisms, inevitably higher trophic level organisms will become contaminated. It is possible that the organisms that consume algae will be unable to reproduce due to the toxic effects of PCBs, allowing unchecked algal growth and subsequent eutrophication of the water body, forcing beach closings. Although it is true that detectable concentrations of contaminants in organism tissue do not necessarily indicate the occurrence of adverse effects, SQC are necessary to prevent contaminants from bioaccumulating to levels higher than adverse effect thresholds. Therefore, sediment quality criteria are a legitimate product of government spending and a helpful tool for natural resource managers.

Sediment quality criteria provide a framework within which managers can determine the health of the ecosystems under their jurisdictions. SQC can serve various purposes, including to:

- Identify areas where there is an increased potential for adverse biological effects 
- Determine whether contaminated areas warrant further assessment or are at concentrations that require no further study

- Assist in focusing studies for research or budget purposes

- Identify the need for source control

- $\quad$ Classify hot spots and rank sites according to the extent and severity of contamination and ecological and human health risks

- $\quad$ Assist in designing monitoring programs and references for status and trends reports

- Identify specific contaminants of concern

- Derive other regulatory requirements that will protect against continued toxic effects

- $\quad$ Provide a consistent assessment of ecological and human health risks

- Measure sediment quality of areas of dredging or underwater construction

- Evaluate the effects of contaminated sediments for baseline environmental risk assessments

- Determine areas needing restoration

\subsection{SQC: Original Development}

Contaminated sediment has been a major environmental concern in aquatic and marine ecosystems along the coasts of North America for decades (IJC 1988). Because industrial and municipal point sources contributed the most pollution to rivers and coastal areas, the main driver for sediment quality criteria was EPA's desire to model effluent concentrations in a way that would lead to a qualification of sediment impact for the National Pollution, Discharge and Elimination System (NPDES). In response to this need, in the early 1960s federal, regional and state agencies began developing numerical criteria and assessment methods for evaluating contaminants in sediment and dredged material (Becker et al. 1989). 
Most early contaminant determinations were based on comparisons between chemical concentrations of individual chemicals in contaminated areas and those in reference sediments without considering biological effects. There are two main flaws with this approach. First, chemical concentrations are not accurate predictors of biological and ecological effects. For example, for the same concentration of chemical in different types of sediment, the percent bioavailability of a contaminant can range from zero to one hundred percent (Burton and Scott 1992). Second, multiple contaminants in the sediment may exhibit antagonistic or synergistic effects that are not accounted for in singlecontaminant tests. For example, some organic compounds have the potential to interact chemically with each other in the sediment, creating a more toxic environment for an organism than if each compound existed in the sediment alone (Broderius et al. 1995, Broderius 1991).

Advances in technology, increases in population pressures in coastal cities such as Boston, and economic growth led to an increase in underwater construction and dredging projects in ports and harbors. The resuspension of sediment caused by such activities exacerbates the exposure of organisms to contaminants and increases not only the rate of bioaccumulation but also the potential for adverse effects. Another issue related to underwater projects involves disposal of dredged material. If material from one area is to be deposited in another area, especially a marine site, it is essential to determine the contaminant concentration and corresponding toxicity of the dredged material to organisms at the disposal site.

In Massachusetts, the Boston Harbor Navigation Improvement Project (BHNIP) involves dredging, resuspension of sediment and disposal of dredged materials. In order to both deepen the shipping channels and remove potentially toxic sediment from the floor of Boston Harbor, hundreds of cubic meters of sediment are being dredged. The top layers of this sediment are anthropologically generated, i.e. laid down after the end of the last glacial age, and is unsuitable for deep ocean dumping due to high levels of contaminants. Much of this sediment, therefore, is being disposed of in designated areas of the harbor. 
Although these dredged materials will be capped to prevent leaching of contaminants into harbor waters, it is unclear how thick the cap needs to be for complete effectiveness, and a miscalculation could lead to increased toxicity of area sediments. These dredging and dumping activities also cause the resuspension of contaminated sediment, increasing the amount of chemicals to which marine organisms are exposed. Because BHNIP activities are increasing the potential for bioaccumulation of contaminants, state officials need some standard by which to quantify and qualify sediment toxicity.

More recently, researchers have been trying to make the connection between sediment contamination and biological effects in order to develop a more accurate set of sediment quality guidelines (Becker et al. 1989). The US Environmental Protection Agency (EPA) is attempting to develop a set of protective numerical criteria generic enough to be implemented on a national level. The EPA's first method involved adapting the 1980 Water Quality Criteria (WQC) to sediment concentrations. WQC are based on a large toxicological database, they are legally binding, and they have proven useful in improving and maintaining the environmental quality of the nation's water (USEPA 1993a). Therefore the similar development of SQC was deemed an appropriate approach (Shea 1988).

There are a few problems with the WQC adaptation to SQC. First, sediment contamination problems are not necessarily connected to poor water quality (USEPA 1990). Discharges of contaminants may meet WQC specification, but partitioning leads to increased concentrations in sediment. Second, because sediments can retain contaminants over time, it is possible that they will remain contaminated even if water column contaminant concentrations are below applicable water quality standards. Higher temporal and spatial variations of contaminant concentrations in water also make accurate assessments of water quality difficult, yet sediments tend to integrate contaminants over time, eliminating some of the variability (Shea 1988). Third, benthic organisms are exposed to water column concentrations in addition to sediment concentrations of contaminants; this dual exposure may render the WQC inadequate (Hull and Suter 1994). 
Fourth, water quality in marine areas is complicated by the large amount of water moved in and out of coastal areas by tidal action.

\subsection{SQC: Current Status}

After an analysis of three different approaches for development of SQC: 1) adaptation of water quality criteria, 2) equilibrium partitioning (EqP) modeling, and 3) sediment bioassays, the EPA chose the EqP approach as the best predictor of sediment quality (DiToro et al. 1991). At the time, (the 1980s) EqP also had the most scientific as well as economic support (Shea 1988). The SQC are to be applied when the total organic carbon in the sediment is greater than 0.5 percent and when the primary route of organism exposure to contaminants is the sediment (USEPA 1998a).

In 1993, the EPA released draft reports for sediment quality criteria for five chemicals: endrin, dieldrin, phenanthrene, acenapthene and flouranthene. The documents were based on the recommendations of technical experts outside the EPA as well as research completed by various offices within the EPA and were entered into the federal register and made available for public comment. Subsequently, however, the documents outlining the SQC for the three PAH compounds were retracted for multiple reasons. The identification of the dissolution and sequestration of PAH molecules into soot particles raised questions of contaminant bioavailability (McGroddy et al. 1996, McGroddy and Farrington 1995) (see Section 7 for more detail on contaminant bioavailability).

Stakeholders who disagreed with the applicability of the equilibrium partitioning method of SQC derivation commented that the guidelines were either too protective or not protective enough (see Section 4 for a more detailed description of stakeholder interests). Some managers, such as Lee and Jones (1992) and the National Research Council (NRC 1989) believe that the EPA has overstated both the capability and the utility of the EqP approach due to multiple technical limitations. Because of these criticisms and new information on partitioning of nonpolar organics, the EPA conducted more research on 
the potential toxicity of all five compounds. The revised reports for endrin and dieldrin will be released in the fall of 1999.

The PAH documents, however, were formally withdrawn. PAHs produce a narcosis effect on organisms, and all PAH compounds studied have caused similar effects on biota (Broderius 1995). Scientists at the EPA therefore assumed that the mode of toxicity for all PAH compounds is comparable and that the toxicity of $\mathrm{PAH}$ compounds in sediment is additive (USEPA Draft) (See Appendix A for more detailed information on PAH compounds). The EPA is now developing a sediment quality guideline for mixtures of PAHs. It is supposed to be published in the federal register for public comment and review in the fall of 1999 (Bell, personal communication). Food web effects, however, are still not taken into account (Berry, personal communication).

The new criteria will be published under a new title: Equilibrium Partitioning Sediment Guidelines (EPSG). The EPA changed the name of the numerical toxicity values from criteria to guidelines because they are not legally enforceable until they are incorporated as state standards (Shea 1988). The EPSG are simply federal recommendations for agencies to refer to when making management decisions. Currently, despite the creation of SQC, there is no universal guidance on the application or uses of SQC available for regional and local managers (USGS 1997). For example, regardless of the EPA's "recommended" criteria, managers could choose any one of a number of SQC for application to a specific site. There is little agreement on which approach provides the most reliable guidelines, the predictability of SQC on a site-specific basis is uncertain and often the cause and effect relationship of contaminant concentrations to adverse biological effects is unclear (USGS 1997). Application can also be controversial because of varying interpretations of the SQC (e.g. managers versus polluters), as most users do not have a clear understanding of how the SQC are derived (USGS 1997). At present, it is unclear which are the "best" sediment contamination guidelines for adequate protection of the entire marine food web. 
No research is currently being done to develop SQCs for PCBs; there is no EPA budget for $\mathrm{PCB}$ research (Berry, personal communication). Although a lot of data on PCBs exist, each congener, or distinct PCB compound, exhibits a different toxicity. PCBs are such persistent bioaccumulative toxins that scientists have found it difficult to predict PCB concentrations in organisms from PCB concentrations in sediment (See Appendix A for more information on PCB congeners).

In the face of these uncertainties, states have responded differently. For example, Washington State developed site-specific SQC for Puget Sound and standardized the results as state criteria (WADEC 1991, Becker et al. 1989). Massachusetts on the other hand, proposed the application of Florida's sediment quality criteria to Massachusetts waters and was turned down by the EPA. More detail on both of these states' SQC can be found in Sections 3 and 4.

There are advantages and disadvantages to both national/regional and site-specific sediment quality criteria (Table 1). Site-specific criteria are a more appealing option because they may be more accurate than a national or regional system of SQC, but the few disadvantages such as high cost may be enough to prevent states from choosing this route. The best approach would be one that combined the positive aspects of each type of criteria: applicable on a state-by-state basis yet requiring little resources for development. 
Table 1

Advantages and Disadvantages of National/Regional versus Site-specific Sediment Quality Criteria (USGS 1997)

\begin{tabular}{|c|c|c|}
\hline & Advantages & Disadvantages \\
\hline $\begin{array}{l}\text { National/Regional } \\
\text { Criteria }\end{array}$ & $\begin{array}{l}\text { Focus preliminary } \\
\text { screening and site } \\
\text { investigations on } \\
\text { specific chemicals } \\
\text { Allow for comparison to } \\
\text { other national/regional } \\
\text { sites } \\
\text { - Provide for consistent } \\
\text { application across sites } \\
\text { Lower cost for the site } \\
\text { manager if SQC are } \\
\text { already established } \\
\text { Provide increased } \\
\text { statistical confidence in } \\
\text { accuracy due to peer } \\
\text { review and derivation } \\
\text { from a large data set }\end{array}$ & $\begin{array}{l}\text { Do not include food } \\
\text { web effects } \\
\text { Lack SQC for many } \\
\text { contaminants of concern } \\
\text { Lack guidelines for } \\
\text { mixtures of } \\
\text { contaminants } \\
\text { Are inadequate for } \\
\text { clean-up standards } \\
\text { Are intended for } \\
\text { application to all } \\
\text { sediment, yet } \\
\text { freshwater, estuarine } \\
\text { and marine systems } \\
\text { differ in biology, } \\
\text { chemistry and ecology }\end{array}$ \\
\hline Site-specific Criteria & $\begin{array}{l}\text { Consider variability in } \\
\text { site characteristics } \\
\text { (biological, chemical } \\
\text { and physical) } \\
\text { Consider contaminant } \\
\text { bioavailability } \\
\text { Can be mixture-specific } \\
\text { May have better } \\
\text { stakeholder acceptance } \\
\text { Allow for the potential } \\
\text { to save on remediation } \\
\text { costs } \\
\text { Decrease uncertainty } \\
\text { through in-situ test } \\
\text { results }\end{array}$ & $\begin{array}{l}\text { Require large amounts } \\
\text { of money/resources in } \\
\text { the short term for SQC } \\
\text { development } \\
\text { May over- or } \\
\text { underestimate organism } \\
\text { sensitivity to } \\
\text { contaminants }\end{array}$ \\
\hline
\end{tabular}




\subsection{Approaches to Sediment Quality Criteria Development}

There are three basic approaches to sediment quality criteria: 1) equilibrium partitioning modeling, 2) laboratory bioassays, and 3) field studies. Equilibrium partitioning modeling relies on the assumption that contaminant concentrations in porewater are in equilibrium with concentrations of the same contaminant in biota and sorbed to sediment. Laboratory approaches rely on the extrapolation of water quality criteria to sediment, modeling of chemical fate in an aquatic system or the extrapolation of laboratory cause and effect studies to field situations. Field-based approaches require empirical chemical and/or biological measures of sediment contamination in order to establish sediment quality values. It is difficult, however, to accomplish accurate field sampling and be able to extrapolate the results from single sample analysis to an entire study area. Collection and storage techniques can affect sediment samples, and both local in-situ effects (e.g. bioturbation) and larger scale effects (e.g. storms) could also cause anomalous contaminant values (Shea 1988). Another general source of uncertainty in the calculation of SQC values is fact that the method by which the available sediment toxicity data are rationalized can be of questionable accuracy (USEPA 1993a).

Within the three above-mentioned categories of SQC derivation, there are over ten specific methods for SQC determination. Some of these approaches are strictly chemical

(e.g. the reference weight-of-evidence approach), others are strictly biological (e.g. the field-collected sediment bioassay approach) (Becker et al. 1989). Out of these approaches, the six that are most commonly used correlate biological response with chemical concentrations measured in sediment. These include the Water Quality Criteria approach (WQC), the Spiked-Sediment Toxicity approach (SST), the Apparent Effects Threshold approach (AET), the Equilibrium Partitioning approach (EqP), the EffectsRange Low and Effects-Range Median approach (ER-L/ER-M), and the Threshold 
Effects Level and Probable Effects Level approach (TEL/PEL). In order to determine the set of SQC most appropriate for use in Massachusetts, the methods of each of these six approaches are described and then each approach is analyzed according to cost, difficulty, applicability and reliability. The benefits and limitations of each approach are summarized in Table 2 at the end of this section. The results of the practicality analysis for each approach are summarized in Table 3 at the end of this section.

\subsection{Water Quality Criteria Approach}

\section{Methods}

The water quality criteria approach to SQC development involves applying previously derived water quality criteria for chemical concentrations in the water column (based on toxicological studies relating chemical concentrations to biological effects) to chemical concentrations in sediment porewater. This follows the assumptions that the quality of marine sediments can be assessed from porewater concentrations and that benthic organisms have the same sensitivities to various contaminants as water column organisms (DiToro et al. 1991). In 1980, the EPA published ambient water quality criteria, i.e. numerical limits that are "EPA's best estimate" of chemical concentrations protective of human health and the presence and uses of aquatic life (e.g. domestic water supply, recreation, navigation, wastewater dilution and wildlife habitat). WQC were developed to be chronic exposure, safe concentrations of the available fraction of potentially toxic contaminants (Lee and Jones 1992).

\section{Cost: Low}

If the contaminants of concern detected at a site have published water quality criteria, then the WQC approach requires little cost or time. For pollutants without WQC such as specific PCB congeners, criteria would need to be developed. Site-specific toxicity tests would also be necessary to augment the WQC, screening for unknowns in sediment and 
determining the impact of those contaminants. These additional tests and newly derived WQC would increase the amount of resources needed for implementation.

The values generated by this approach to SQC are often considered conservative (see Reliability section below for detail). Managers therefore may view this approach as a non-cost-effective option; conservative criteria might require more time and money for remediation than would be necessary under the different criteria values of other approaches (Lee and Jones 1992). In terms of long-term ecosystem health, however, overprotection is better than underprotection; it is costly and often not feasible to undo damage to an ecosystem.

\section{Difficulty: High}

While this approach mainly uses previously established criteria, eliminating the necessity of biological measurements of field samples, application requires determination of the porewater concentration of contaminants. Accurate porewater measurements are difficult due to the large volume of porewater required and the technical difficulties involved in taking samples. Complications can multiply because there are no standard sampling and analysis procedures. Difficulty also increases when WQC do not exist for site-specific contaminants of concern and new criteria need to be derived.

\section{Applicability: High}

WQC were derived for the express purpose of wide applicability to all sites, but because of various data gaps (e.g. lack of WQC for all contaminants of concern) the correlation between sediment quality and biological effects can be tenuous.

\section{Reliability: Low}

WQC are based on large toxicological databases developed for specific contaminants and therefore are statistically reliable, yet probable uncertainties and errors associated with the water quality criteria approach exist. For example, WQC may be conservative numerical values for protection because the criteria assume that all forms of a chemical 
present in the water are equally toxic. Often the case is that some forms of a compound are less toxic than others. In contrast, the potential for underprotection also exists. WQC assume that porewater exposure is the only route of contamination, but ingestion of contaminated material may be a significant source of a chemical to biota. WQC also do not account for chemical interactions (antagonistic or synergistic).

Lack of any standardized method for measuring interstitial water also leads to difficulties when comparing values derived from different studies at different sites. In general, the WQC approach to SQC development is almost outdated: stricter regulations on effluent and better waste disposal practices have improved water quality, but sediment acts as a sink and therefore has both historical and present-day contamination.

\subsection{Spiked Sediment Toxicity Approach (or Spiked Sediment Bioassay Approach)}

\section{Methods}

The spiked sediment toxicity (SST) approach to sediment quality criteria development is a dose-response relationship derived by exposing test organisms to sediments that have been inoculated with a known concentration or amount of chemical or chemical mixture (Chapman 1989). It can be used to develop a cause and effect relationship between specific chemicals and biological responses. Once organisms are exposed to contaminated sediment, mortality and/or sublethal effects are recorded. A dose-response curve is calculated and threshold toxic levels in the sediment are derived. Some proponents of this method believe that it is the only reliable method for testing interactive effects because lab controls can be imposed (Becker et al. 1989). In terms of the application of site-specific guidelines, the SST method is often used for permitting of dredging activities and benthic survey programs, and the EPA is currently developing standard toxicity test protocols for various endpoints for multiple organisms. 


\section{Cost: High}

A large amount of time and money would be required to develop site-specific criteria for multiple organisms and multiple compounds under the SST approach. Any results would also need field validation, raising the cost and time needed to do the assessment even higher.

\section{Difficulty: Moderate}

State-of-the-science allows for accurate testing and quality assurance/quality control (QA/QC) protocols, but there may be difficulty in obtaining resources to perform the required tests.

\section{Applicability: High}

This type of testing is suitable for all classes of chemicals and most types of sediment (MacDonald et al. 1992). The SST approach is best suited for measuring acute adverse effects, because depending on the length of time the tests are conducted, results may not accurately reflect chronic effects.

\section{Reliability: Moderate}

The results of spiked sediment toxicity testing show direct cause-effect relationships between contaminant-specific concentrations and adverse biological effects. The approach is similar to the approach used to develop the EPA's water quality criteria, and therefore both the procedure itself and the reasoning behind it are already deemed technically and legally acceptable (Hull and Suter 1994). Currently, the methods for SST testing are not standardized, decreasing the comparability of results.

Because chemicals can be tested alone or in combination, lab conditions often simulate chemical field conditions and indicate appropriate cause-effect relationships (Hull and Suter 1994). The SST approach requires results to be extrapolated to varied field situations, however, depending on site-specific characteristics, this can negatively affect 
the reliability of the results. For example, a contaminant may occur in the sediment as multiple compounds or in different forms. Accurate extrapolation of lab results to the study site would require the chemical used in the spiked bioassay to contain the same range and proportions of a contaminant's compounds. This, however, is difficult to assure (Lee and Jones 1992, Persaud et al. 1992).

Another reliability issue involves the equilibration time for nonpolar organics, which may be longer than the length of time the test is conducted. It is possible that input of a fresh amount of contaminant to sediment would not allow for adequate aging, causing the contaminant to appear more toxic than a comparable amount of the same contaminant in the field (Lee and Jones 1992). Short test runs also may not allow for fulfillment of an organism's bioaccumulation potential and will not show food web effects (MacDonald et al. 1992), nor does SST account for field sediment contaminant bioavailability.

\subsection{Apparent Effects Threshold Approach}

\section{Methods}

An Apparent Effects Threshold (AET) for a chemical is the concentration in sediment above which statistically significant biological effects (related to reference conditions) would always be expected to occur (Becker et al. 1989, USEPA 1989). A scoring is developed for a group of sediments based on empirical values assigned to a number of sediment characteristics, typically bulk chemical composition, benthic faunal analysis and sediment bioassays (Lee and Jones 1992). For nonionic organic compounds, AETs are based on the dry-weight normalized concentrations of total organic carbon (MacDonald et al. 1992). Matched (i.e. synoptically collected) data on sediment chemistry, benthic infaunal effects and sediment bioassays can be integrated to determine the concentration of contaminant above which all samples for a specific biological indicator exhibit adverse effects. Levels for both acute and chronic effects can be determined. When the 
concentration of a contaminant in the sediment exceeds the AET value, then the sediment is "polluted" and requires some type of remediation.

\section{Cost: High}

This approach requires extensive data collection for multiple chemical variables and at least one biological indicator, making this approach to SQC determination both costly and time-consuming. Bioaccumulation tests for first level sediment-to-benthic invertebrate contaminant transfers can also increase assessment costs by thousands of dollars per sample (Becker et al. 1989).

\section{Difficulty: Moderate}

State-of-the-science allows for accurate testing and quality assurance/quality control (QA/QC) protocols, but there may be difficulty in obtaining resources to perform the required tests. Although this method can interpret bioaccumulation data, organismspecific factors such as age, sex, reproductive state and physiological state still need to be considered. This makes the data difficult to normalize and apply.

\section{Applicability: Low}

AETs can be established for biological indicators (e.g. toxicity to fish) that reflect areawide conditions (i.e. over multiple sampling stations) on a site-specific basis (Becker et al. 1989). This allows AETs to treat sediment as part of a dynamic system rather than the "black box" of field sampling and sediment bioassays. There are no constraints on either the types of chemicals that can be used in this approach or the endpoints that can be measured. These thresholds may also be applied to intertidal areas, but because organisms in these ecological zones are often less sensitive to environmental changes than their marine sub-tidal counterparts, the AETs generated may not be conservative enough estimates. They may also be used to derive the effects of combinations of chemicals. 
Chemical, physical and biological differences between sites prevent cross-site application. The fact that AETs are site-specific can in some ways be seen as a benefit to using the approach, but it is also a limitation, as their use outside of the original site is severely restricted. For example, it was found that the AET values calculated by Becker et al. (1989) for Puget Sound, WA were not applicable to California sediments.

\section{Reliability: Moderate}

Because AETs indicate levels above which adverse biological effects are always observed, the values are easily defensible; the method relies on objective statistical criteria for determining adverse effects. Bioaccumulation can also be accounted for as concentrations in the tissue of higher trophic levels can be correlated with sediment concentrations over time.

AETs do not prove cause and effect relationships between contaminants and effects. Instead, they merely identify the concentration of a contaminant that is associated exclusively with adverse biological effects. Use of an empirical relationship between the sediment concentrations of a contaminant and a biological response (e.g. determined from toxicity testing) can lead to inaccurate determinations of the significance of contaminants in sediment (Lee and Jones 1992). Without adequate sampling intensity, however, there may not be enough data to represent the wide range of chemical concentrations and biological effects often found in the field.

It is also possible that AETs are not conservative enough for benthic protection; some biological effects occur at chemical concentrations below the determined threshold (Hull and Suter 1994, Becker et al. 1989). AETs assume that any other chemical and/or environmental variables to which biota are exposed affect organisms well below the AET, which may be incorrect, e.g. if contaminants have additive effects. AETs are developed through a comparison with reference conditions, but there is no standard method for defining an appropriate reference area, nor have reference area screening 
criteria been established. This implies that the AET approach needs one set of criteria in order to develop a second.

When AETs were established for Puget Sound, Washington, their reliability was evaluated through both sensitivity and efficiency analyses. Sensitivity is "the proportion of all stations exhibiting a particular adverse biological effect that are correctly predicted using sediment quality values for that biological indicator" (Becker et al. 1989 p.19). Efficiency is "the proportion of all stations predicted to have particular adverse effects that actually are impacted" (Becker et al. 1989 p.19). Once combined, sensitivity and efficiency lead to a reliability estimate that measures "the proportion of all stations for which correct predictions were made for either the presence or absence of adverse biological effects" (Becker et al. 1989 p.19). AETs were found to be adequately reliable for Puget Sound (Becker et al. 1989), but have not been adopted elsewhere.

\subsection{Equilibrium Partitioning Approach}

\section{Methods}

The Equilibrium Partitioning approach to sediment quality criteria development is an attempt to model the tendency of a chemical to move into one environmental compartment versus another, deriving a bulk sediment chemical concentration benchmark. For SQC derivation, the compartments are porewater, sediment organic carbon and biota. The approach is based on the following premises:

- contaminants in one environmental phase (e.g. sediment) are in continuous exchange with other phases (e.g. porewater and biota)

- contaminant distribution between phases is predictable based on the chemical and physical properties of each phase (MacDonald et al. 1992, Shea 1988)

- all environmental phases are at equilibrium 
- sensitivity of benthic organisms to contaminant levels is the same as that of water column organisms (DiToro et al. 1991)

- exposure to and uptake of contaminants are equal for all biota

- porewater is the primary route of exposure

- the octanol-water partition coefficient $\left(\mathrm{K}_{\mathrm{ow}}\right)$ reliably predicts the partitioning of a chemical between organic carbon in the sediment and porewater.

The results of the EqP approach are contaminant-specific numerical values. The biological effects of the contaminant concentrations in the sediment can then be estimated using appropriate water quality criteria and partition coefficients for contaminants between aqueous and solid phases. A correction for organic carbon is also made because it is the dominant sorption phase for nonionic organic chemicals and is assumed therefore to be the primary control on bioavailability (USEPA 1993a). The equations for SQC derivation are:

$$
\begin{aligned}
& \mathrm{SQC}=\mathrm{K}_{\mathrm{p}} * \mathrm{WQC} \\
& \text { and } \mathrm{K}_{\mathrm{p}}=\mathrm{K}_{\mathrm{oc}} * \mathrm{f}_{\mathrm{oc}}
\end{aligned}
$$

where:

$\mathrm{SQC}=$ sediment quality criterion (ug contaminant in sediment $/ \mathrm{kg}$ sediment)

$\mathrm{K}_{\mathrm{p}}=$ water-sediment partition coefficient ( $\mathrm{L}$ water $/ \mathrm{kg}$ sediment)

$\mathrm{WQC}=$ water quality criterion (ug contaminant in water $/ \mathrm{L}$ water)

$\mathrm{K}_{\mathrm{oc}}=$ organic carbon-water partition coefficient (g organic carbon / L water)

$\mathrm{f}_{\mathrm{oc}}=$ fraction of organic carbon ( $\mathrm{g}$ organic carbon / g sediment)

$\mathrm{K}_{\mathrm{oc}}$ is related to $\mathrm{K}_{\mathrm{ow}}$. Both the relationship and the values of $\mathrm{K}_{\mathrm{ow}}$ for various nonpolar organics can be found in the literature (Hemond and Fechner 1994, Thomann 1989, Hawker and Connell 1988, Chiou 1985).

$\mathrm{SQC}$ based on the EqP approach can be predictive of biological effects because final acute values (FAV) and final chronic values (FCV) are imbedded within the WQC. The final acute value is the concentration of a contaminant below which 95 percent of all 
organisms are protected. The final chronic value is approximately the lowest contaminant concentration at which fifty percent of the organisms are acutely affected (LC50). Therefore, the equilibrium partitioning equation for SQC can also be written:

$$
\begin{aligned}
& \mathrm{SQC}=\mathrm{K}_{\mathrm{p}} * \mathrm{FAV} \\
& \text { or } \mathrm{SQC}=\mathrm{K}_{\mathrm{p}} * \mathrm{FCV} \quad \text { (USEPA 1993a) }
\end{aligned}
$$

where:

$\mathrm{FAV}=$ final acute value

$\mathrm{FCV}=$ final chronic value.

According to the EPA (USEPA 1993b), the assumption that the contaminant sensitivity of benthic organisms is similar to that of water column organisms is supported by the results of the following comparisons:

- acute values for the "most sensitive" benthic organisms versus the "most sensitive" water column species

- acute values for all benthic species versus acute values for all WQC organisms for all chemicals standardized to LC50 values

- FCV and FAV calculations for a single species versus all species

- the individual components of the benthic community versus all species.

\section{Cost: Low}

Using the existing EPA water quality criteria toxicological database, EqP eliminates the need to collect new biological data and cuts down on time and cost. It relies on other information such as partition coefficients that are readily available in the literature and requires little data on other physical or chemical site-specific characteristics.

EqP cannot be used easily for chemicals that are not assigned a WQC. For example, there is a WQC for total PCBs, but none exist for individual PCB congeners. Research 
has shown that some congeners are more toxic than others, and with the analytical capabilities of current scientific instrumentation, it is possible to measure sample concentrations of each congener (Hull and Suter 1994). This would require increased expenditures to develop new criteria for contaminants of concern not included in the WQC database.

\section{Difficulty: Low}

Modeling concentrations in the porewater from sediment concentrations is easier than directly measuring porewater contaminant concentrations for nonionic chemicals. In order to arrive at the free chemical concentration in the porewater, direct measurements require subtracting the amount of dissolved organic carbon and its corresponding sorbed contaminants from the total, which can be a difficult process (USEPA 1993a). It is easier to assume that the free contaminant in the porewater is in equilibrium with the sediment organic carbon and therefore a direct estimate of sediment contamination (Hull and Suter 1994).

Difficulty increases when WQC do not exist for site-specific contaminants of concern and new criteria need to be derived.

\section{Applicability: High}

EqP can be applied to all sediments because of the intrinsic assumption of the similarity of sediment characteristics across sites, but is best used for sediments with a fraction of organic carbon $\left(f_{o c}\right)$ greater than 0.5 percent (Becker et al. 1989). When the $f_{o c}$ is less than 0.5 percent, factors controlling second order effects on partitioning such as particle size and sorption to the non-organic mineral fraction are relatively more important (Hull and Suter 1994, USEPA 1989).

\section{Reliability: Moderate/High}

The EqP approach to SQC determination creates a direct relationship between cause and effect of sediment-associated contaminants and biological adverse effects. Statistical 
reliability is high because EqP-derived values use the existing large, contaminant-specific EPA water quality criteria toxicological database.

Aside from the uncertainty associated with any model, in terms of equilibrium partitioning the actual field situation is more complex than the EqP model assumes. Of the three components of the modeled system, biota, sediment and porewater, none are homogenous. Growth stage and reproductive status affect the uptake of contaminants by organisms, and interspecies variations exist as well. Partitioning into the sediment can be affected by both chemical and physical variables. For example, sediment is often polluted with more than the one contaminant analyzed; it can contain complex mixtures of varying chemical species that can interact on an antagonistic or synergistic basis. Physical sediment characteristics also affect partitioning; contaminants in sandy and coarse grain sediment have a lower partition coefficient than finer-grained sediment (Shea 1988). The EqP approach is also based on the total organic carbon (TOC) fraction in the sediment. While there is some technical basis for using the total organic carbon content of sediment to estimate the detoxification potential of sediments for nonpolar organics, there are a variety of potential technical problems with TOC-normalization (Lee and Jones 1992). For instance, the assumption that the $\mathrm{K}_{\mathrm{ow}}$ adequately predicts partitioning may be inaccurate because the various types of organic matter than can be present in sediment can have different sorption kinetics and capacities (Lee and Jones 1992).

The EqP assumption of reversible equilibrium (Karickhoff 1984) may be inaccurate because of contaminant bioavailability and bioaccumulation issues. For example, PAHs are sequestered in the soot fraction of the sediment and therefore are not available for uptake by organisms (McGroddy et al. 1996, McGroddy and Farrington 1995). Colloidal material in the porewater may carry sorbed contaminant, thereby affecting the accuracy of predicted concentrations. There may also be some dilution of porewater contaminants to overlying water, negating the assumption of perfect equilibrium between phases (Lee and Jones 1992). 
The biological assumption of similar contaminant sensitivity between benthic and water column organisms is also in question. The tests relied upon by the EPA for validation of this assumption used mainly amphipods, yet the benthic community is much more diverse and therefore may still exhibit varying sensitivity (USEPA 1993a). The analyses of test results compare different endpoints and do not take bioaccumulation or food web effects into account when analyzing higher trophic level organisms (USEPA 1993a).

For the EqP approach to be valid, equilibrium needs to be reached within the period of testing (usually 28 days), but biological and chemical processes as well as phase transfer of contaminants may take longer (Shea 1988).

\subsection{Effects Range-Low and Effects Range-Median Approach (Long et al. 1995)}

\section{Methods}

The Effects Range-Low and Effects Range-Median (ER-L/ER-M) approach to sediment quality criteria was developed by Long and Morgan (1990) and updated to its present version by Long et al. (1995). It provides a set of values that correlate sediment contamination with adverse biological effects without causality. The data for ER-L/ER$M$ derivation is contained in a Biological Effects Database for Sediments (BEDS), which integrates data from over 350 studies throughout North America. Types of data include EqP modeling, laboratory spiked-sediment bioassays, AET data and field studies of sediment toxicity and benthic community composition. Only matching, synoptically collected biological and chemical data from marine and estuarine studies is included in the database. BEDS data also covers a wide range of benthic effects due to contaminant concentrations such as measures of altered benthic communities, histopathological disorders and the significance of elevated toxicity. 
BEDS is divided into "effects" and "no-effects" data sets. In the effects data set, all the data points show some adverse biological effect at a certain contaminant concentration. There is an apparent concordance between observed biological responses and measured chemical concentration. The no-effects data set contains all contaminant concentrations for which no adverse effects were observed. Only the effects data were used in the determination of ER-L and ER-M values, and the data distribution was determined using percentiles: the ER-L occurs at the tenth percentile and the ER-M occurs at the fiftieth percentile. This minimizes the influence of outlier data points (MacDonald et al. 1996, Long et al. 1995). The minimal effects range (where adverse effects are rarely observed) defines where the concentration of a contaminant is less than the ER-L, the possible effects range (where effects occasionally occur) delineates where the contaminant concentration falls between the ER-L and the ER-M, and the probable effects range (where effects frequently occur) is where the concentration of a contaminant is greater than the ER-M.

Reliability tests were conducted for the results of the ER-L/ER-M derivations. If the guidelines derived from BEDS were within a factor of three or less when compared to other guidelines, then the ER-L and ER-M were deemed reliable. The incidence of adverse effects had to be less than 25 percent in the minimal effects range, greater than 75 percent in the probable effects range and show a corresponding increase of effect with increased concentration. The results of the reliability tests showed that guidelines for all classes of PAHs and most individual PAH compounds were highly accurate, while the results for PCBs were only moderately reliable.

\section{Cost: Low}

The cost for using the ER-L/ER-M method of SQC derivation is minimal because the values are already published. Cost would only increase if a criterion did not exist for a contaminant of concern detected in the field and therefore needed to be determined for full assessment of a specific site. 


\section{Difficulty: Low}

Use of the ER-L/ER-M approach requires straightforward application of relevant criteria to specific sites. Difficulty would increase only if a criterion did not exist for a contaminant of concern detected in the field and therefore needed to be determined for full assessment of a specific site.

\section{Applicability: High}

The ER-L/ER-M guidelines take into account multiple organisms and incorporate many different endpoints. They can be applied directly to sediments with multiple contaminants, as many of the studies included in BEDS had data from sites with contaminant mixtures. This also allows ER-Ls and ER-Ms to be applied over a wide range of sediment organic carbon fractions.

\section{Reliability: Moderate}

One of the most common criticisms of the ER-L/ER-M approach to SQC development is that the results are correlative rather than descriptive of direct cause and effect values, making the accuracy of this application uncertain. The ER-L/ER-M guidelines are not normalized to total organic carbon because most data sets included in BEDS did not report that information. The guidelines also do not account for bioavailability, assuming that this information would be intrinsically included in the data from each study in BEDS. Bioaccumulation is included in the ER-L/ER-M for some organisms, but food web effects are not. While the BEDS database does include some higher trophic level organisms such as sea urchins, bivalve data is rare and the majority of the data points are the results of amphipod sediment toxicity studies. Because the ER-L and ER-M guidelines do not include the no-effects data set, there is the possibility that the ER-L values are biased high and are underprotective for the more sensitive species.

Upon application of these guidelines to sites along the coast of the United States, NOAA found that the ER-L guidelines fail to distinguish among toxic and non-toxic sites. For example, ER-L exceedances occur frequently (in 348 out of 612 sites studied $=57$ 
percent), but the guidelines do not assist in associating chemical concentration with effect. Sediments with no contaminant concentrations above the ER-L are probably not toxic, but given an exceedance of the ER-L value, the guidelines are of limited use (NOAA 1999). Thirty-three percent of the same sites examined around the coastal US had contaminant concentrations that exceeded the ER-M; these sites are probably all toxic (NOAA 1999).

Although one of the benefits of the ER-L/ER-M approach is that BEDS includes studies where organisms were exposed to mixtures of contaminants in sediment, the criteria were developed for single chemicals. There is no way to prove that the adverse effects measured are directly correlated to one specific contaminant or another. The same degree of response was associated with the concentration of each individual chemical contaminant measured in the sediment independent of the cause of the biological response (Lee and Jones 1992). The numerical criteria therefore cannot be directly translated into toxic effects on aquatic life, but simply indicate areas where adverse effects due to contamination could occur.

\subsection{Threshold Effects Level and Probable Effects Level Approach (MacDonald et al. 1996)}

\section{Methods}

MacDonald et al. (1996) used a weight of evidence approach in order to calculate the threshold effects level (TEL) and the probable effects level (PEL) as sediment quality criteria. They are correlative values originally developed to provide widely applicable guidelines for data evaluation under NOAA's National Status and Trends Program. The initial methodology for development of TEL/PEL guidelines is similar to that described above for ER-L/ER-M guidelines and involves analysis of the BEDS database. In this case, however, both the effects and the no-effects data sets were used to define the TELs and PELs for 34 analytes. The TEL is the geometric mean of the fifteenth percentile of 
the effects data set and the fiftieth percentile of the no-effects data set. It indicates the estimated concentration of a chemical below which adverse effects rarely occur. The PEL is defined as the fiftieth percentile of the effects data set and the eighty-fiftieth percentile of the no-effects data set, and indicates the estimated concentration of a contaminant above which adverse effects frequently occur. The range of chemical concentrations greater then the TEL but less than the PEL indicates concentrations at which adverse effects occasionally occur.

The accuracy of the TEL and PEL were tested according to three criteria: 1) comparability, 2) predictability, and 3) reliability. The results of the evaluation indicated a high degree of concordance between contaminant concentrations and the incidence of adverse effects on biota. There was a high degree of reliability for TELs and PELs for most PAH compounds, but low reliability for total PCBs. TEL/PEL values were not determined for individual PCB congeners.

TELs are usually lower than corresponding guidelines from other approaches, indicating that the TELs are more protective of benthic organisms. Due to the nature of the data from which the TELs and PELs were derived, the guidelines are more predictive of chronic, sublethal effects than acute, lethal effects.

\section{Cost: Low}

The cost for using the TEL/PEL method of SQC derivation is minimal because the values are already published. Cost would only increase if a criterion did not exist for a contaminant of concern detected in the field and therefore needed to be determined for full assessment of a specific site.

\section{Difficulty: Low}

Use of the TEL/PEL approach requires straightforward application of relevant criteria to specific sites. Difficulty would increase only if a criterion did not exist for a contaminant 
of concern detected in the field and therefore needed to be determined for full assessment of a specific site.

\section{Applicability: High}

The TEL/PEL guidelines do not establish absolute sediment quality values but ranges for sediment contaminant evaluation. They can be applied to a wide range of organisms and endpoints and can be used for sediments with mixtures of contaminants. In many cases, BEDS may include site-specific data as the database is large and contains studies from sites all over North America.

\section{Reliability: Moderate/High}

The TEL and PEL guidelines consider both effects and no-effects data, and outlier data points do not have a significant effect on the results. The TEL/PEL approach, however, does not fully support the quantitative analysis of cause and effect because it is based only on an association of contaminant concentration and adverse biological effects. Other chemical, physical or biological variables could be causing the recorded adverse effects (e.g. interactions between chemicals or biota reproductive status). The accuracy of the TELs and PELs is constrained by the amount of available data; there is a large body of literature on the acute effects of chemicals on organisms, but chronic effects data is much more limited. The guidelines also do not take the potential for bioaccumulation or variations in bioavailability into account. It is difficult to compare the TEL/PEL guidelines with guidelines developed using other approaches because not many SQC were derived relative to the number of contaminants of concern. 
Table 2

Summary of the Benefits and Limitations of Six Approaches to Sediment Quality Criteria Derivation

\begin{tabular}{|c|c|c|}
\hline SQC Approach & Benefits & Limitations \\
\hline $\begin{array}{l}\text { Water Quality } \\
\text { Criteria }\end{array}$ & $\begin{array}{l}\text { Based on a large } \\
\text { toxicological database } \\
\text { Based on specific } \\
\text { contaminants } \\
\text { Requires only porewater } \\
\text { measurements }\end{array}$ & $\begin{array}{l}\text { Does not account for } \\
\text { ingestion of contaminated } \\
\text { material } \\
\text { Does not account for } \\
\text { chemical interactions } \\
\text { - Lack of standard method for } \\
\text { porewater measurements } \\
\text { - Does not exist for all } \\
\text { contaminants of concern } \\
\text { Does not account for } \\
\text { bioavailability, } \\
\text { bioaccumulation or food web } \\
\text { effects }\end{array}$ \\
\hline $\begin{array}{l}\text { Spiked Sediment } \\
\text { Toxicity (Spiked } \\
\text { Sediment Bioassay) }\end{array}$ & $\begin{array}{l}\text { - Shows direct cause-effect } \\
\text { relationships } \\
\text { - Suitable for all types of } \\
\text { classes and sediments }\end{array}$ & $\begin{array}{l}\text { Lab results need to be } \\
\text { extrapolated to field } \\
\text { conditions } \\
\text { - Requires significant time and } \\
\text { money } \\
\text { - May not reflect chronic } \\
\text { effects } \\
\text { - Test methods are not } \\
\text { standardized } \\
\text { Does not account for } \\
\text { contaminant bioavailability }\end{array}$ \\
\hline $\begin{array}{l}\text { Apparent Effects } \\
\text { Threshold }\end{array}$ & $\begin{array}{l}\text { Easily established for } \\
\text { indicators reflecting site- } \\
\text { wide, site-specific conditions } \\
\text { - Relies on objective statistical } \\
\text { criteria to determine adverse } \\
\text { effects } \\
\text { - Can be applied to all } \\
\text { chemicals, endpoints } \\
\text { - Accounts for } \\
\text { bioaccumulation }\end{array}$ & $\begin{array}{l}\text { Does not provide cause-effect } \\
\text { relationships } \\
\text { - Requires significant time and } \\
\text { money } \\
\text { - May not account for effects } \\
\text { occurring below the threshold } \\
\text { - Requires definition of } \\
\text { "reference area" for which } \\
\text { there are no standards } \\
\text { - Restricted use outside of } \\
\text { specific site } \\
\text { Does not account for food } \\
\text { web effects }\end{array}$ \\
\hline
\end{tabular}


Table 2 Continued

\begin{tabular}{|c|c|c|}
\hline SQC Approach & Benefits & Limitations \\
\hline $\begin{array}{l}\text { Equilibrium } \\
\text { Partitioning }\end{array}$ & $\begin{array}{l}\text { Uses WQC database and } \\
\text { other literature data } \\
\text { Applicable to almost all } \\
\text { sediment types } \\
\text { Determines direct cause and } \\
\text { effect between contaminant } \\
\text { concentration and organism } \\
\text { effects }\end{array}$ & $\begin{array}{l}\text { Does not account for site- } \\
\text { specific characteristics } \\
\text { Does not account for } \\
\text { bioavailability, } \\
\text { bioaccumulation or food web } \\
\text { effects } \\
\text { - Cannot be derived for } \\
\text { chemicals without WQC } \\
\text { Assumption of reversible } \\
\text { equilibrium may not be } \\
\text { accurate }\end{array}$ \\
\hline $\begin{array}{l}\text { Effects Range-Low / } \\
\text { Effects Range-Median }\end{array}$ & $\begin{array}{l}\text { Accounts for multiple } \\
\text { contaminants } \\
\text { Incorporates multiple } \\
\text { endpoints } \\
\text { - Applicable to multiple sites } \\
\text { - Requires little time or money }\end{array}$ & $\begin{array}{l}\text { Does not establish cause and } \\
\text { effect between contaminant } \\
\text { concentration and organism } \\
\text { effects } \\
\text { - Not normalized to organic } \\
\text { carbon } \\
\text { Does not account for food } \\
\text { web effects } \\
\text { Does not include no-effects } \\
\text { data } \\
\text { Fails to distinguish } \\
\text { adequately between toxic and } \\
\text { nontoxic sites }\end{array}$ \\
\hline $\begin{array}{l}\text { Threshold Effects } \\
\text { Level / Probable } \\
\text { Effects Level }\end{array}$ & 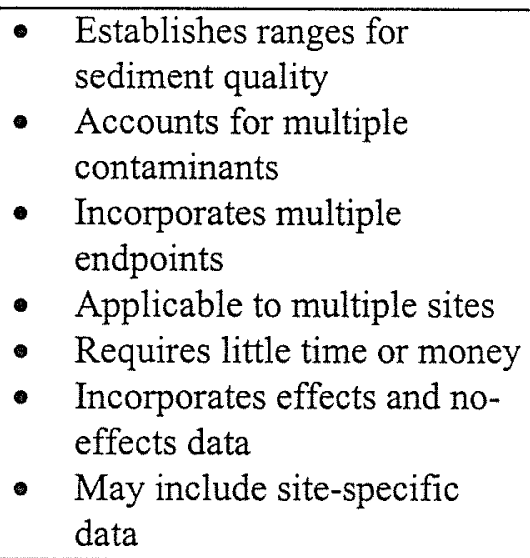 & $\begin{array}{l}\text { Developed for few } \\
\text { contaminants } \\
\text { Does not establish cause and } \\
\text { effect between contaminant } \\
\text { concentration and organism } \\
\text { effects } \\
\text { - Not normalized to organic } \\
\text { carbon } \\
\text { Does not account for food } \\
\text { web effects }\end{array}$ \\
\hline
\end{tabular}




\begin{tabular}{|l|c|c|c|c||}
\hline \multicolumn{5}{|c|}{ Table 3 } \\
Overall Rating of Four Attributes of Six Approaches to Sediment Quality Criteria \\
Derivation \\
\hline \hline Approach & Cost & Difficulty & Applicability & Reliability \\
\hline $\begin{array}{l}\text { Water Quality } \\
\text { Criteria }\end{array}$ & Low & High & High & Low \\
\hline $\begin{array}{l}\text { Spiked } \\
\text { Sediment } \\
\text { Toxicity }\end{array}$ & High & Moderate & High & Moderate \\
\hline $\begin{array}{l}\text { Apparent } \\
\text { Effects } \\
\text { Threshold }\end{array}$ & High & Moderate & Low & Moderate \\
\hline $\begin{array}{l}\text { Equilibrium } \\
\text { Partitioning }\end{array}$ & Low & Low & High & Moderate/High \\
\hline $\begin{array}{l}\text { Effects Range- } \\
\text { Low / Effects } \\
\text { Range-Median }\end{array}$ & Low & Low & High & Moderate \\
\hline $\begin{array}{l}\text { Threshold } \\
\text { Effects Level/ } \\
\text { Probable } \\
\text { Effects Level }\end{array}$ & Low & Low & High & Moderate/High \\
\hline \hline
\end{tabular}




\subsection{Stakeholders and Their Interests}

Aside from choosing a method of SQC derivation from the multitude of options currently available, one of the most controversial issues in SQC application involves the missions of the agencies and other stakeholders that have interests in marine areas. The main stakeholders in sediment quality issues include but are not limited to:

- federal agencies: the US Environmental Protection Agency (EPA), the US Army Corps of Engineers (ACOE), the US Fish and Wildlife Service (USFWS) and the National Oceanic and Atmospheric Administration (NOAA)

- state agencies: the MA Department of Environmental Protection (DEP), the Massachusetts Environmental Policy Act Unit (MEPA), and the MA Coastal Zone Management Agency (CZM)

- non-governmental organizations (NGOs)

- industry.

Conflicting mandates and overlapping jurisdictions create friction between users of sediment quality guidelines (Figure 1). Federal agencies such as the EPA and the ACOE drive sediment quality regulations because of their respective roles in environmental health, enforcement of NPDES and marine construction, while the US Fish and Wildlife Service and NOAA are relegated to a more advisory role. On the state level, resource managers have the option of adopting the EPA "recommended" SQC. Because these criteria are not required, the various agencies within the state bureaucracy, each concerned with a different aspect of implementation and enforcement of SQC, attempt to further their own interests. The public is involved in the issue of SQC development to the extent that it has the power to influence and put controls on government agencies. With the public's ability to sue and its access to the press, SQC proponents must be aware of the public's interests. Industries are also concerned with SQC development and its 
subsequent application and enforcement, as they function within environmental response economics and attempt to keep environmentally-derived costs to a minimum.

The next section reviews each stakeholder according to the following characteristics:

- regulatory authority to be involved in or concerned with SQC

- mandates

- interests

- jurisdiction.

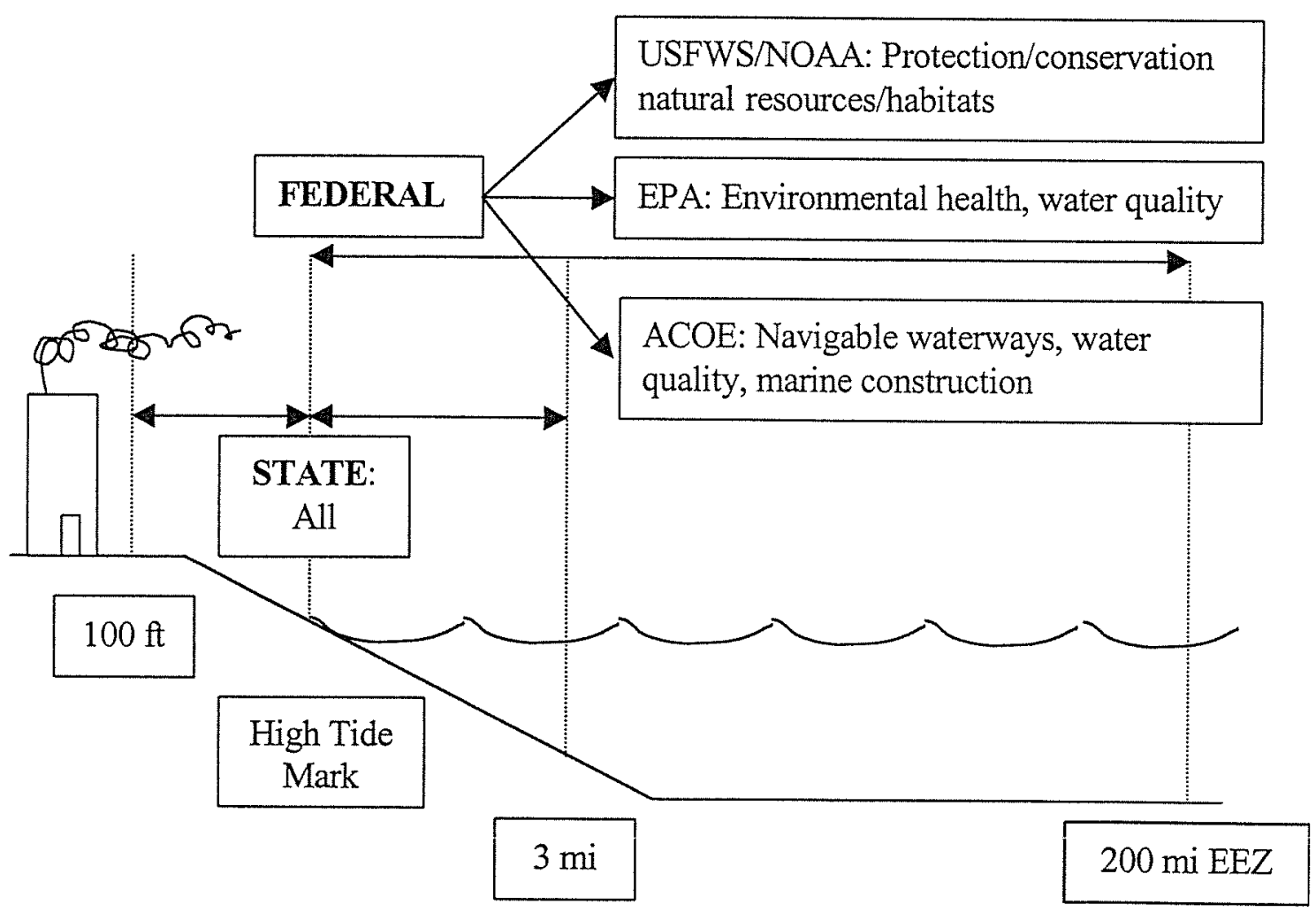

Figure 1. Diagram of the jurisdictions of various federal and state agencies involved in marine sediment quality. 


\subsection{The US Environmental Protection Agency (EPA)}

\section{Authority}

The EPA receives its authority to develop SQC for the protection of benthic organisms from Sections 304(a)(1) and 118(c)(7)(C) of the Clean Water Act (CWA) of 1977, the reauthorization of the CWA in 1987, the National Environmental Policy act of 1969 and the Marine Protection, Research and Sanctuaries Act of 1972.

\section{Mandates}

These pieces of legislation make the EPA responsible for protecting the chemical, physical and biological integrity of the nation's waters (USEPA 1993a). This includes but is not limited to environmental attributes such as fisheries productivity, marine biodiversity, ecosystem stability and human health. The EPA also has the power to approve or veto ocean-based projects (e.g. dredging) if the agency determines the project will cause excessive adverse effects on the environment.

Numerous offices within EPA are responsible for different aspects of these missions. The Office of Water is involved in the development of SQC because it is mandated to maintain national water quality and is therefore concerned with the water quality effects of dredging and remediation projects. The Office of Science and Technology funds the Office of Research and Development (ORD) to design and implement research protocols and standards such as toxicity testing and bioaccumulation experiments. ORD is responsible for determining the state-of-the-science and considering the feasibility of wide applications of their results.

\section{Interests}

It is necessary to note that while the EPA may publish SQC as agency recommendations, there are internal disagreements on SQC use and application. The Office of Water will push for more conservative SQC because of the impact that resuspended sediments and their corresponding contaminant loads can have on water quality. Managers in the EPA 
Dredging Office, however, believe that SQC are not adequate when applied to dredging projects for many of the reasons that the ACOE opposes SQC (see Sections 4.2 and 5) (Tomey, personal communication).

\section{Jurisdiction}

The EPA has jurisdiction over all waters, sediments and other natural resources for purposes of ecosystem and human health protection.

\subsection{The US Army Corps of Engineers (ACOE)}

\section{Authority}

The US Army Corps of Engineers receives its authority from the Rivers and Harbors Act of 1899, the Marine Protection, Research and Sanctuaries Act of 1972 (Ocean Dumping Act) and Section 404 of the Clean Water Act.

\section{Mandates}

The ACOE has three major mandates: 1) to keep the waterways and harbors of the United States open for navigation, 2) to preserve water quality, and 3) to control the discharge and disposal of dredged materials into marine waters. The agency is in charge of permitting state, local and federal dredging projects (which must be approved not only by the ACOE but by the MA Office of Coastal Zone Management, the EPA and the state water quality office). The ACOE is also required to conduct biotests on dredge materials to determine whether there are detectable concentrations of contaminants such as oil pollution-related compounds, PCBs, pesticides, mercury, cadmium or any mutagenic, teratogenic or carcinogenic compound. Upon detection of any one of these chemicals, bioaccumulation bioassay tests and water column toxicity tests must be conducted to assess potential adverse effects on higher trophic level organisms. 


\section{Interests}

Because of the ACOE's almost total involvement in marine construction projects, the agency has a vested interest in SQC. In general, the ACOE would prefer no national SQC. Such widely applicable criteria would not be site-specific enough to determine the exact cause(s) of potential or actual toxicity, and the ACOE may be required to implement unnecessary remediation measures. This could increase project costs exponentially.

The ACOE has itself a conflict of interest because it receives money from the federal government for dredging projects, and it is therefore to the agency's advantage to make the dredging projects happen.

\section{Jurisdiction}

The ACOE has jurisdiction over any construction or dredge/fill activity seaward of the mean high water mark. As noted earlier, however, unless there is a matter of national security, the ACOE can be overruled by the EPA.

\subsection{The US Fish and Wildlife Service and the National Oceanic and Atmospheric Administration (USFWS and NOAA)}

\section{Authority}

The USFWS and NOAA have the authority to protect natural resources affected by sediment quality under many federal regulations, including: the Fish and Wildlife Coordination Act of 1958, the National Environmental Policy Act of 1969, the Marine Protection, Research and Sanctuaries Act of 1969, the Federal Water Pollution Control Act (as amended), the Estuary Protection Act, the Coastal Zone Management Act of

1972, the Wild and Scenic Rivers Act, the Endangered Species Act of 1973, the Fishery Conservation and Management Act of 1976 (as amended) and the Wetlands Protection Act. 


\section{Mandates}

The USFWS and NOAA are required to protect the wildlife and the aquatic habitats of the United States respectively. They are responsible for assessing the impacts of all water- and land-related resource development projects on fish and wildlife. Because sediment is the base of the natural ecosystem, the USFWS and NOAA are subsequently concerned with sediment quality and sediment quality criteria.

\section{Interests}

Because these agencies are required to protect wildlife and habitat including both endangered species and commercial resources, they are interested in conservative SQC. Criteria and corresponding bioaccumulation data would need to result in contaminant concentrations lower than the species-specific toxicity thresholds for each contaminant.

\section{Jurisdiction}

The USFWS and NOAA have jurisdiction over all natural resources for purposes of protection and conservation. The majority of legislation under which these agencies function, however, is relatively weak compared to the powers of the EPA and the ACOE. For the most part, USFWS and NOAA depend on the co-operation of the EPA and the ACOE, the only major exceptions being issues that fall under the Endangered Species Act or the Wetlands Protection Act.

\subsection{Massachusetts State Agencies}

\section{Authority}

Massachusetts state agencies have the authority to implement SQC under the Massachusetts General Laws and the Federal Water Pollution Control Act. 


\section{Mandates}

There are various state agencies involved in projects or issues that require information on sediment quality. The Massachusetts Environmental Policy Act Unit (MEPA) collects information on proposed projects, determines the potential for adverse effects due to project implementation and makes permitting recommendations to the MA State Executive Office of Environmental Affairs. The MA Department of Environmental Protection (DEP) issues permits for construction, dredging or filling projects in the tideland areas of the coast. It also ensures that any such projects in any waterways and wetlands under state jurisdiction are in compliance with state water quality standards. The MA Coastal Zone Management Agency (CZM) has the legal authority to determine whether federal projects (e.g. dredging) or federally funded projects within the coastal zone are consistent with state coastal policies.

\section{Interests}

Where MEPA would advocate conservative SQC to minimize potential adverse effects from sediment contamination, the DEP would prefer more liberal SQC, as the DEP can only approve permits and receive funding for projects that will not cause an exceedance of the criteria values. Because Massachusetts does not have any state-approved SQC and the EPA has not yet published nationally recommended criteria, the only major consistency issue for the CZM is protection and preservation of coastal resources, possibly leaning the agency toward a more conservative set of SQC.

Because the regulations surrounding dredging are promulgated on a national level and federal agency approval is required for permitting, the states do not usually take the initiative in water or sediment quality issues. Washington State is one exceptionresource managers there created an entire set of AET-derived SQC for Puget Sound (Becker et al. 1989). For the most part, states do not want to spend money (Burgess, personal communication). Determining sediment chemistry and applying that to acceptable contamination levels is cheaper than most other testing; toxicity tests are approximately $\$ 1000$ per sample for each species (dredge permitting requires two 
species) and bioaccumulation tests are on the order of $\$ 5000$ (Burgess, personal communication). Waiting for the federal agencies to derive SQC and then applying them to sites within each state, however, is the cheapest option for state resource managers. States can create state sediment quality standards either by accepting national guidelines or adopting SQC values that are more conservative than the federal recommendations. At least Massachusetts has taken the initiative in remaining involved in this issue; a dredged material management plan is in progress and the state has made some money available to research use of SQCs.

\section{Jurisdiction}

The state has jurisdiction over any activities within its territorial waters, i.e. between (up to) one hundred feet landward of specified major landmarks, roads, etc. to three miles seaward of the baseline.

\subsection{Non-governmental Organizations (NGO)}

\section{Interests}

Most often environmental advocates of clean water and conservation of natural habitat, NGOs are involved in sediment quality issues to ensure adequate protection for aquatic ecosystems. Some NGOs are more concerned with effects of contaminants on human health and therefore support more conservative SQC to eliminate the potential bioaccumulation of contaminants to harmful levels. The power of most NGOs lies in their ability to sue the government, to place political pressure on agencies by influencing voters and to use the media. 


\subsection{Industry}

\section{Interests}

As the main suppliers, emitters and disposers of the EPA's contaminants of concern, industries and other polluters are focused on protecting company interests and profitability. This implies acceptance of only the most liberal SQC or the refusal to adopt any SQC at all. For quasi-government agencies/industries such as Massport, environmental response economics dictate their agendas; they have both business interests as well as environmental concerns. 


\subsection{Conflicting Issues in SQC Development and Application}

Review of the various agencies and stakeholders highlights multiple conflicts of interest both intra- and inter-agency/interest group. For instance, to fulfill its mandates, the EPA developed SQC for three PAH compounds and two pesticides. These were derived using the equilibrium partitioning approach, resulting in criteria that protect 95 percent of all organisms. If the organism being adversely affected by contamination is a member of an endangered species, however, according to the USFWS and NOAA 95 percent protection is not adequate. Various NGOs, because of their activist roles in environmental issues, may also believe that the EqP-derived SQC are too liberal. The Army Corps of Engineers and industries have the opposite complaint; they consider the SQC unnecessarily conservative. Although a chemical may not be responsible for the adverse effects evinced by biota, if the contaminant exists in sediment at concentrations greater than the criterion, remediation is still required

Because the EqP approach was chosen by the EPA yet SQC were developed without an economic feasibility study for application (Bell, personal communication), some stakeholders maintain that the costs of meeting the SQC are unreasonably high for the presumed environmental benefit. To industries, the conservativeness of the SQC will force them to adapt their emissions or change their waste disposal procedures in order to comply. For the ACOE, high costs are exacerbated for two reasons. The first is the fact that EqP-derived SQC cannot be used for environmental assessment. Federal law prohibits dredging projects from using contamination models (e.g. the EqP model) at any site. Instead, the ACOE is required to run laboratory bioassays on two different species of amphipod. Sediment chemistry is used to direct the sampling and determine which chemicals need to be examined in greater detail, i.e. require biological testing. There was an attempt to change this restriction, but because of conflicting interests, lack of 
coordination between parties and bureaucratic red tape, the issue was eventually dropped without resolution (Tomey, personal communication). While there has been some sort of agreement between the ACOE and the EPA on use of SQC, the terms of the agreement are not yet available for public consideration (Bell, personal communication).

The second cost issue that concerns the ACOE as well as other federal and state natural resource managers is that meeting the sediment quality standards can involve many technical difficulties. SQC implementation might lead to an unnecessary and high increase in the costs of municipal and industrial wastewater treatment and contaminated sediment disposal (Lee and Jones 1992). For example, if the recommended SQC misjudge the amount of bioavailable contaminants and overestimate sediment toxicity, the amount of "extra" sediment that needs to be removed could easily increase clean-up costs by an order of magnitude. For scale, remediation approaches can range from hundreds to thousands of dollars per cubic meter of sediment without achieving comparable environmental benefit (Lee and Jones 1992).

While the EPA's interaction with the states is usually on a support level, there are still conflicts of interest between the EPA and the states on the use and application of SQC. For example, almost two years ago, Massachusetts sent a proposal to the EPA to use the TEL/PEL sediment quality guidelines derived for Florida (MacDonald et al. 1996) for their state criteria. The EPA rejected this proposal for two reasons. The first was that there are five coastal states in EPA Region 1 and CZM consistency needs to be upheld. Only Massachusetts proposed use of the TEL/PEL guidelines and the EPA did not want other states proposing the adoption of different standards. Different standards might also cause sediment contaminant concentrations that pass in one state to fail in another. This could lead to disposal of all dredged material in the state waters with the least stringent criteria. The second reason for refuting the proposal was that EPA believes that the EqP approach for deriving SQC is the best (for reasons already mentioned), and would prefer that the states adopt a modeling approach rather than an empirically derived set of criteria (Tomey, personal communication). 
The EPA is developing sediment quality guidelines for application to aquatic systems, but there may be an error in the way the EPA has advertised SQC. The criteria are intended for use as guidelines, not hard and fast boundaries of or pass/fail criteria for sediment quality. There is simply a good chance of toxic effects above the guidelines. The values derived using the EqP method have not been published in the peer-reviewed literature because there are so many caveats to the numbers, yet the EPA still fears that states will adopt the SQC as unbendable thresholds (Burgess, personal communication).

As much as the continued conflicts between stakeholders may appear to hamper any progress in terms of SQC development or application, it is important to note that the diversity of interests and agendas prevents dominance of any one extreme. For example, while organizations like NGOs have a conservative approach towards many environmental issues, e.g. no dredging anywhere, the ACOE's interests lie at the other end of the spectrum, e.g. dredge anything and everything. Due to these disparities, often the solution lies somewhere in the middle of the conservative-liberal continuum, allowing maximum benefit for the most number of parties, including the environment itself. 


\subsection{Appropriate Guidelines for Massachusetts Marine Sediments}

With the ubiquitous contamination currently in the environment, it is essential that managers have an adequate tool to address the potential for chemically induced adverse effects on ecosystem and human health. In many environmental compartments, e.g. the atmosphere or groundwater, contamination is transient; dispersion, dilution or degradation of the chemical into less toxic forms can mitigate long-term impacts. Marine ecosystems, however, provide a long-term sink for contaminants. Chemicals such as $\mathrm{PAH}$ and $\mathrm{PCB}$ compounds, once they have entered the water column, sorb to or dissolve into particles and settle out to bottom sediment. Massachusetts' marine sediments, for example, contain detectable and potentially harmful concentrations of both types of contaminants. Subsequent accumulation of contaminants in sediment is the first step in a process of bioaccumulation and biomagnification of compounds throughout the entire food web. The challenge resource managers now face is to improve the quality of sediments to contaminant levels that minimize the potential for adverse effects. Areas requiring remediation need to be identified and then the suitability of dredged sediment for open-ocean disposal must be determined.

This issue is not a new one, yet the question of whether a widely applicable, accurate tool for assessing sediment quality exists has not been answered. Sediment quality criteria have been proposed as a solution, but none have been universally accepted. The two main reasons for this lack of consensus are scientific uncertainty and diverse stakeholder interests. There are multiple methods for deriving SQC, each with its own benefits and limitations (Table 2), but the varied results from each approach highlight the uncertainties inherent in SQC derivation. Even in the case of similar criteria, however, stakeholders' interpretations of the data may not agree. Conflicting interests over issues such as economic benefit, difficulty of implementation, range of applicability, scientific 
reliability and overall protectiveness direct the priorities of those involved. It is necessary, therefore, to create an option for sediment quality management that integrates the widest range possible of interests.

The EPA currently maintains that the Equilibrium Partitioning modeling approach to SQC derivation is the most accurate. Using this method the agency has developed SQC for two pesticides and is in the process of determining criteria for PAH mixtures. These SQC are nationally recommended sediment quality values. They are intended to assist state- and local-level managers in making decisions regarding sediment quality. Some care must be taken in applying sediment quality criteria, however. The EPA has already changed the name of these values to "guidelines" rather than "criteria" in an attempt to remind users that these are not hard and fast rules for toxicity. Rather they are estimates and should be incorporated with other site-specific field data for better accuracy. A more effective title might be sediment quality screening criteria. As screening criteria, these derived values would indicate sites that required more intense testing for toxicity determination versus those sites which were below all toxicity thresholds.

Although the EPA recommends use of only the EqP approach, after the review and analysis in Sections 2-5 of this document, a combination of two SQC approaches are recommended for the state of Massachusetts. The Threshold Effects Level and Probable Effects Level approach together with EqP modeling would provide a balance augmenting the benefits and offsetting the limitations of each approach (Sections 3.4 and 3.6). For example, while the EqP approach simplifies site characteristics by assuming reversible equilibrium and ignoring site-specific physical, chemical and biological characteristics, it does illustrate a definitive cause and effect relationship between contaminant and organism. The TEL/PEL guidelines, because they are derived from actual field and laboratory measurements, intrinsically account for issues such as sediment type, porewater chemistry and contaminant bioavailability but only show correlative effects between contaminant concentration and organism effects. 
The TEL/PEL and EqP approaches to SQC derivation also meet the criteria by which stakeholders judge the appropriateness and feasibility of SQC utilization. Application of both types of SQC would incorporate the following factors: 1) the most conservative guidelines for the least time and money, 2) criteria that can be applied to sediments with chemical mixtures, 3) criteria that can be adapted to include site-specific data by additions to the BEDS database, and 4) criteria that can predict chronic, sublethal effects as well as acute effects. Both approaches are low cost, low difficulty, high applicability and moderate/high reliability methods. Swartz (1999) has shown that criteria derived from EqP and ER-L/ER-M approaches are similar, therefore a defensible combination of EqP and TEL/PEL should be possible.

To test this conclusion, EqP and TEL/PEL values could be applied on a trial basis to various sites off the Massachusetts coast. This would allow managers to determine the appropriateness of using these effects levels as sediment quality screening criteria. Successful application would allow normalization of the evaluations of all state marine waters and allow local and state managers to be consistent in their monitoring and recommendations for continued benthic protection. Neither of these approaches, however, accounts for biomagnification of contaminants to higher trophic level organisms and therefore ignores potential food web effects. Contaminant bioaccumulation and subsequent transfer need to be incorporated in order for resource managers to adequately protect ecosystem and human health. 


\subsection{Bioaccumulation}

Sediment contamination primarily occurs in nearshore areas, especially urban harbors and ports. Chemical inputs to the marine system most often settle out within a small radius of their source, concentrating the contaminants in coastal areas. As legislative controls on point-source pollution have increased, the emphasis on marine pollutants has shifted to secondary sources such as non-point source runoff, atmospheric input, groundwater leachate and the re-introduction of sediment associated pollutants due to resuspension. Resuspension can occur from physical processes such as waves, currents, storms or tidal movement, from biological processes such as organism burrowing (though this may be more of a factor for mobile benthic organisms rather than bivalves) or from humaninduced activities such as underwater construction, dredging operations or boating. In general, it is only after some resuspension event that contaminants make their way to the deep-sea bottom.

Organisms within the marine ecosystem may be exposed to site-specific contaminants that could be bioaccumulated. Bioaccumulation of potentially toxic chemicals occurs through various exposure routes, including diffusion across body walls and ingestion of contaminated water, particles and prey. For benthic organisms in contact with sediment, the risk of accumulating toxic levels of contaminants is increased relative to water column organisms because sediment acts as a sink for pollutants (Salomons et al. 1987).

As concentrations of contaminants in organism tissue increase, small-scale adverse effects, i.e. those on a cellular level, may expand and affect entire organs or systems within an individual organism. While one affected organism may not be cause for concern over ecosystem health, exposure of many organisms in a population to a contaminant and biomagnification of these contaminants through the food web can lead to large numbers of impaired individuals in multiple species. Bioaccumulation is often 
considered an indicator of potential adverse effects from contaminants. Lethal effects of high contaminant concentrations are immediately obvious and may decimate a species (e.g. fish kills), but more subtle chronic effects occur as well. For example, dysfunction of the reproductive system due to high contaminant concentration in soft tissue could ultimately lead to population depletion and disruption of the natural ecosystem (McDowell and Shea 1997) (Figure 2). The higher an organism in the food web, the higher the probability that it will accumulate toxic levels of a chemical, and over time all organisms including top human consumers are affected. While it is true that not all contaminants bioaccumulate or biomagnify, in general, bioaccumulation is a cause of concern for resource managers and policy makers who have the dual tasks of maintaining ecosystem integrity and protecting both human and ecosystem health.

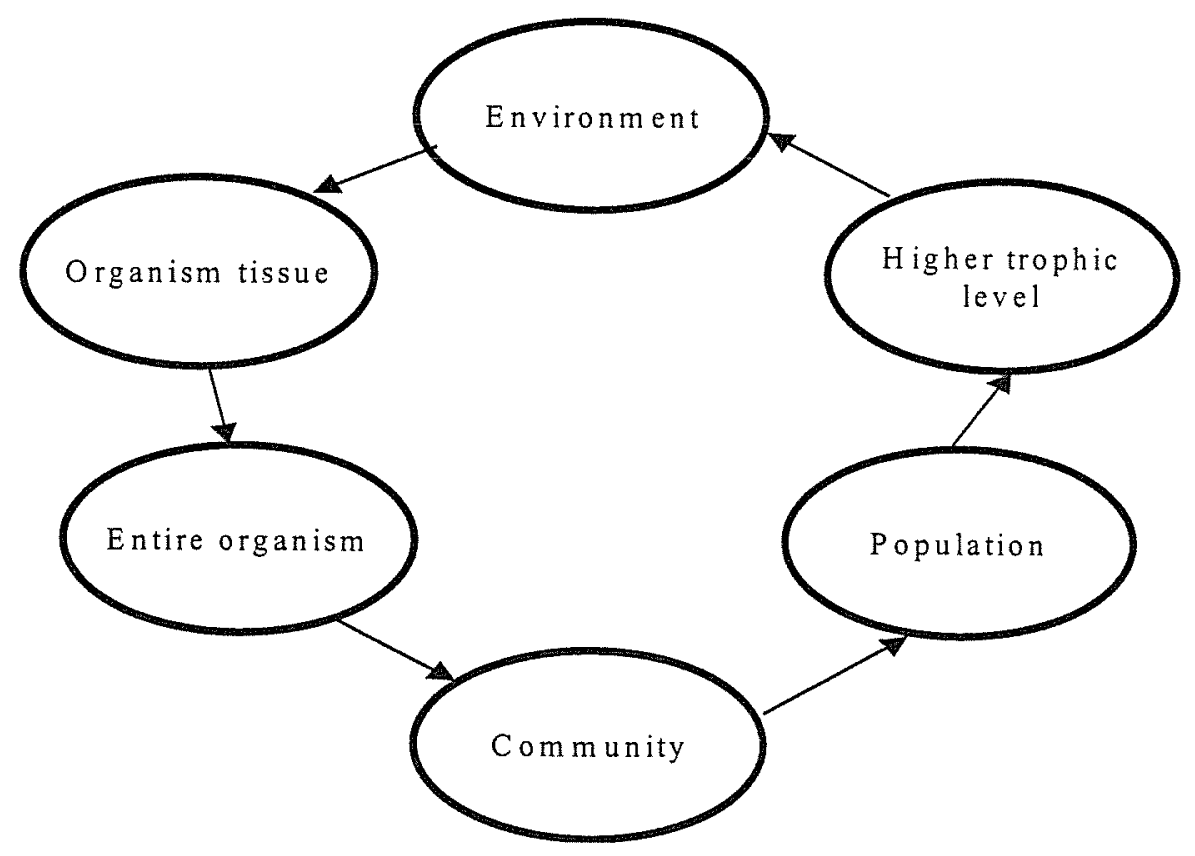

Figure 2. Diagram of the relationship between bioaccumulation of contaminants from environmental media to organisms and biomagnification of effects from individual organisms to populations and eventually to the ecological community. 


\subsection{Influencing Factors}

The accumulation of sediment-associated contaminants depends on the characteristics of the compound, sediment, porewater and organism toxicokinetics. Oxygen content and temperature may also affect bioaccumulation rates.

\section{Characteristics of Organic Chemicals}

Both the partitioning characteristics and kinetics of nonpolar organic compounds govern their environmental fate. High hydrophobicity causes PCBs and PAHs to dissolve readily into organic carbon in sediment and into lipid in biota. For this reason, accumulation factors and partition coefficients are lipid and organic carbon normalized, allowing contaminant concentrations between organisms and across sites to be comparable. Contaminants also partition to seawater, the ratio depending on their affinity for colloidal organic material and other suspended microparticles (Baker et al. 1986). The concentrations in the various phases (sediment, aqueous and biota) however, do not necessarily exist in equilibrium. For example, in some estuaries the contaminant concentration of PAHs in sediment is over a thousand times greater than the concentration in both the dissolved and dispersed phases (Menon and Menon 1999). This disparity is due mainly to the sequestration of PAHs in the sediment and assumed to be a characteristic of other nonionic organic compounds as well (Menon and Menon 1999).

Bioaccumulation varies both with molecular weight and $\mathrm{K}_{\mathrm{ow}}$. Compounds with high molecular weights and a $\mathrm{K}_{\mathrm{ow}}$ of approximately 6 have the highest bioaccumulation potential. As $\log \mathrm{K}_{\mathrm{ow}} \mathrm{s}$ move away from this value in either direction, accumulation decreases (Stange and Swackhammer 1994). Compounds with low molecular weights and low $\mathrm{K}_{\mathrm{ow}} \mathrm{s}$ have less of a tendency to partition out of water than their bigger or more hydrophobic counterparts. As molecules get extremely large, however, or have very high $\log \mathrm{K}_{\mathrm{ow}}$ (greater then approximately 6), steric hindrance may prevent uptake. 


\section{Sediment Characteristics}

Organic carbon content and bioavailability are the two most significant variables that need to be considered in bioaccumulation calculations. Organic carbon partitioning has been discussed in the previous section. Bioavailability is a measure of the amount of contaminant environmentally available to biota and is affected by several factors, e.g. sediment composition. For example, due to their planar structure, soot particles can sequester PAH molecules, rendering them unavailable for partitioning into porewater and therefore to biota (McGroddy et al. 1996, McGroddy and Farrington 1995). This decreases the bioavailable fraction of PAH compounds in the sediment.

There have been various attempts to quantify the bioavailable fraction of contaminants, but they are complex, time-consuming methods not usually employed by managers. Most of these methods require an assumption of equilibrium, which may not accurately describe the relationship between contaminant concentrations in sediment, porewater and benthically-coupled biota. Determination of the fraction of sediment Available for Equilibrium Partitioning (AEP) is one of the most accurate predictors of bioavailability because it uses direct field measurements. This method requires measuring the "bound" fraction of contaminant, either to colloids in the porewater or to organic matter in the sediment, and subtracting the bound fraction from the measured total contaminant.

Other attempts at quantifying the bioavailable fraction of sediment contamination include comparisons of chemical bioaccumulation in biota exposed to whole sediment, overlying water and porewater. Some researchers found that exposure to the three compartments resulted in similar accumulation (Harkey et al. 1994), while other analyses showed that tissue $\mathrm{PCB}$ concentrations in bivalves were most closely related to overlying water contaminant concentration (Bergen et al. 1993). Because these studies were performed in the laboratory, however, the bioavailability issues associated with field sediments were eliminated, decreasing the applicability of the results.

Other sediment characteristics that should be noted include contaminant concentration, 
sediment diagenesis (or mineralization) and grain size. If contaminants exist in the sediment in trace amounts, they may not interfere or react with each other, eliminating the possibility of synergistic or antagonistic effects. This does not, however, eliminate the possibility of inter-chemical effects once the contaminants are concentrated in an organism. Sediment aging can also affect contaminant availability through the process of diagenesis. Any resulting change in the chemical's structure can affect its chemical extractability from the sediment (Landrum 1989). This is mainly relevant when laboratory studies are extrapolated to field situations; lack of diagenesis in lab experiments may incorrectly estimate the bioavailable fraction of contaminant in field sediment. Grain size may also need to be considered in an analysis of bioavailability, as many organic contaminants have a higher affinity for finer-grained particles (Landrum 1989).

\section{Porewater}

Contaminants in porewater are sorbed to colloidal material and purely dissolved in seawater. It is important to determine the contaminant concentration in each of these phases and its relative importance to bioaccumulation. However, there is no scientific consensus on this issue. Some studies consider the dissolved phase to be the primary bioavailable phase of contaminants to aquatic organisms (DiToro et al. 1991). Others determined that isolated colloids and sediment contained similar fractions of organic carbon, but as colloids have a greater specific surface area, they may also have more accessible organic material than sediment into which the contaminant can dissolve (Baker et al. 1986). This would make colloidal concentration the dominant control of bioaccumulation from porewater. Still other research, however, has concluded that no one phase is dominant with respect to bioaccumulation (Burgess and McKinney 1999, Harkey et al. 1994). These discrepancies are more understandable in light of the fact that contaminant concentrations in porewater are difficult to measure and there may be some associated error that affects the reliability of results. There is also no standard method for extraction, leading to several different procedures used by laboratories, thereby making results less comparable. 


\section{Organism Toxicokinetics}

While some benthic organisms have the ability to metabolize nonpolar organics, mollusks lack the physiology to convert these compounds into less toxic forms (Anderson 1985, Stegeman 1985). In addition, mollusks do not readily excrete PAH or PCB compounds (Tanacredi and Cardenas 1991). These kinetics allow high concentrations of contaminants to become concentrated in biota tissue over time. Fortunately for the organism, the accumulation of nonpolar organic compounds from sediment is slow, often requiring months to achieve steady state. For example, even benzo[a]pyrene, a contaminant with a high $\mathrm{K}_{\mathrm{ow}}\left(\log \mathrm{K}_{\mathrm{ow}}=6.50(\mathrm{CRC} 1995)\right)$ may take over a year to achieve steady state in amphipods (Landrum 1989).

For benthically-coupled organisms there are various possible contaminant exposure routes, the two main routes being dermal exposure from porewater or overlying water and ingestion of contaminated sediment, water and food. Multiple exposure routes may cause the organism to have tissue concentrations of contaminants higher than sediment concentrations. For example, the filter-feeder Mya arenaria is exposed to environmental contaminants in ambient bottom water or porewater through direct contact of the mantle, gills and outer surface of the gonads (Moreno et al. 1992) and by ingestion of food from the water column. This contaminant intake from particle-associated contaminants causes filter feeders to accumulate larger concentrations of contaminant in their tissue than would be expected from dissolution alone (Menon and Menon 1999). The relative importance of each of the two pathways (aqueous and ingestion) can be estimated by the ecological behavior of the organism, i.e. the relationship between feeding rate and uptake clearance, which differs between organisms with varied feeding habits. For example, filter feeders accumulate higher molecular weight PCBs more effectively than deposit feeders and therefore accumulate higher concentrations over time (Burgess and McKinney 1999). This may occur because the uptake clearance from water is greater than for sediment (Landrum 1989). Contaminant concentrations in filter feeders and deposit-feeders are unaffected by digestive processes or passage through the gut (Boese et 
al. 1996).

Some authors suggest that ingestion by one organism may decrease the amount of chemical available for other organisms assuming the "freely dissolved pool" is limited (Landrum 1989), but in this document the assumption of infinite availability is used.

\subsection{Existing Models}

\section{Biota-Sediment Accumulation Factors / Biological Accumulation Factors}

A common and widely used predictor for contaminant concentrations in benthicallycoupled organisms is the biota-sediment accumulation factor (BSAF) or biological accumulation factor (BAF). A BSAF is the ratio of contaminant concentration in the organism to contaminant concentration in the sediment, and a BAF is the ratio of contaminant concentration in the predator organism to contaminant concentration in the prey. This method is easily applicable for two reasons: 1) it only requires two data inputs, and 2) many accumulation factors have been published in the literature and can be applied to other sites. Published BSAFs, however, do not take into account any biological or chemical variations in organisms, sediment or exposure and therefore are limited in accurate application. The same is true for site-specific accumulation factors: physical, chemical and biological characteristics incorporated into the BSAF may not be similar across sites. For example, BSAFs for PAH compounds vary with changes in season, space and the fraction of sedimentary organic carbon (Maruya et al. 1997). The degree to which an organism is associated with sediment, i.e. infaunal or epifaunal, does not necessarily change its exposure to nonionic organic contaminants (Tracey and Hansen 1996).

Various studies have determined BSAFs for PAHs and PCBs in bivalves, but results vary widely. For example, there are both intra- and inter-species variability in BSAF values for each chemical compound. Maruya et al. (1997) found a significant difference 
between the BSAFs of two clam species, P. amurensis and T. japonica. Tracey and Hansen (1996) had opposite results, which showed that overall BSAF values for both types of nonpolar organic compounds were similar among species and habitat types. Some general trends, however, are evident. The mean BSAF for PCBs is always higher than that for PAHs (Tracey and Hansen 1996), and highly chlorinated PCBs (e.g. 9-10 chlorines) tend to have lower BSAF values than PCBs with four to seven chlorines.

\section{Pharmacokinetic (Toxicokinetic) Model}

In order to describe the uptake, distribution and excretion of various contaminants, a physiologically based pharmacokinetic model (PBPK) is often used. This type of model breaks down the organism into a series of compartments (usually different organs) and utilizes a mass balance approach to connect each compartment via biological processes or products (Figure 3 ). These models can be adapted to multiple species and exposure regimes by modifying appropriate variables. The large number of variables needed to run the model, however, precludes easy use.

While this model may be effective for predicting the outcome of laboratory situations, there are important field variables often not considered. For example, the model may assume infinite dilution of the contaminant in the water column, i.e. zero, and therefore the bivalve tissue contaminants would decrease over time as contaminants dissolved into the "cleaner" water running through its system (Moreno et al. 1992). Filter feeders, however, are exposed not only to overlying water but also to sediment and interstitial water. Sediment, specifically because it acts as a contaminant sink, may be a continuous source of chemicals to the porewater and therefore to the organism, increasing exposure. That ingestion of contaminated particles is not considered is another limitation of the PBPK model (Moreno et al. 1992).

\section{Hydrophobicity (Equilibrium partitioning) Model}

The hydrophobicity, or equilibrium partitioning model assumes that uptake and elimination can be described by first order kinetics, i.e. that contaminants undergo 
Figure 3. Physiologically based pharmacokinetic bioaccumulation model for Mya arenaria (Moreno et al.1992).

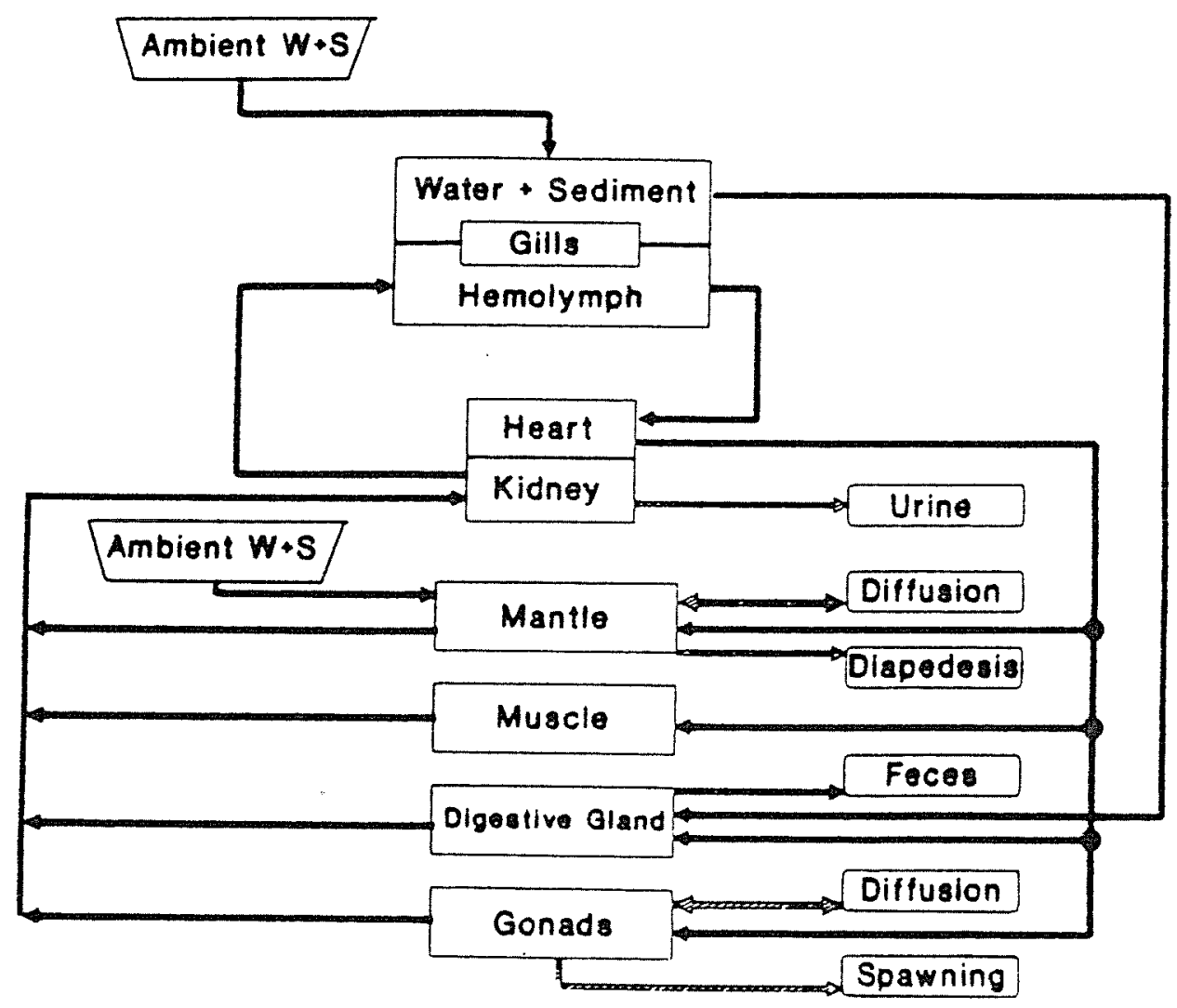


equilibrium partitioning between sedimentary porewater and the lipid phase of the organism. Relationships between bioaccumulation factors and $\log \mathrm{K}_{\mathrm{ow}}$ s have been published showing good correlation between the two variables over wide ranges (Maruya et al. 1997). Over narrow $\log \mathrm{K}_{\text {ow }}$ ranges, however, the BAF cannot be estimated accurately (Barron 1990).

Hydrophobicity models also do not take into consideration any biological variables that may affect organism uptake and subsequent bioaccumulation of a contaminant. The number of exposure routes and the rate of uptake clearance are two important parameters. Steric properties of various chemicals can affect the uptake and distribution of contaminants (e.g. molecular size or $\log \mathrm{K}_{\mathrm{ow}}$ ) (Shaw and Connell 1984). Yet uptake and elimination rates are also influenced by environmental factors. For example, PAH and PCB concentrations in Mya arenaria have been reported that are not in equilibrium with sediment concentrations (McDowell and Shea 1997). This causes contaminant bioaccumulation and subsequent biological effects to be more complicated than the hydrophobicity model is able to predict.

\section{Theoretical Bioaccumulation Potential Model}

Each of the above-mentioned models has some limitation that decreases the predictive capability of the results or limits use and applicability. Three requirements for a model that is not only accurate but also helpful to resource managers are: 1) has wide use and applicability, 2) considers sediment, organism and environmental characteristics, and 3) requires limited data input. One model that has been developed along these lines and is currently used for site assessment of contaminated sediments is the Theoretical Bioaccumulation Potential (TBP) developed by the Army Corps of Engineers (USEPA and USACOE 1991). A type of hydrophobicity model, the TBP is used in the ACOE tiered system of environmental testing and was developed under the following assumptions: sediment and biota are in equilibrium, all nonpolar organic chemicals in the organism are in the lipid, all nonpolar organic chemicals in the sediment are associated with the organic carbon fraction, all chemicals are bioavailable and chemicals are not 
degraded. The formula describing the TBP is:

$$
\mathrm{TBP}=\mathrm{BSAF} *\left(\mathrm{C}_{\mathrm{s}} / \% \mathrm{TOC}\right) * \% \text { Lipid }
$$

where:

$\mathrm{BSAF}=$ bioaccumulation factor of contaminant in sediment to contaminant in organism [ng contaminant in organism/ng contaminant in sediment]. The ACOE uses a default BSAF of 4 for all nonpolar organic chemicals and all organisms.

$\mathrm{C}_{\mathrm{s}}=$ concentration of contaminant (nonpolar organic) in the sediment in any units $\% \mathrm{TOC}=$ percent of total organic carbon expressed as a unitless decimal $\%$ Lipid $=$ percent of lipid in the organism expressed as a unitless decimal $\mathrm{TBP}=$ potential amount of contaminant in an organism on a whole-body wet-weight basis in the same units of concentration as $\mathrm{C}_{\mathrm{s}}$. If data exists as dry weight or dry weight percentages, however, then the TBP is expressed in the same units as the sediment concentration on a soft tissue-dry weight basis.

This model was tested using sediment and clam contamination data from Massachusetts Bay for various PCB and PAH compounds (Table 4, Figure 4) (McDowell and Shea 1997) (see Section 8 for more detail regarding the data set). Testing of the TBP model using this high quality, reliable data set (McDowell and Shea 1997) showed that for all compounds model predictions are inaccurate. Most PCB concentrations are underpredicted by a factor of 2-8 (Table 4). As seen in Figure 5, however, as PCB concentrations in $M$. arenaria decrease to less than 12 [ng of contaminant/g sediment], empirical concentrations are overpredicted. The model overpredicts almost all PAH concentrations in clams between a factor of 3 and 220 (Table 4, Figure 6).

It is possible that the discrepancies between empirical and theoretical results are due to the generic BSAF used by the ACOE in the TBP model. Therefore, the BSAF of 4 was replaced with bivalve-specific, compound-specific BSAFs averaged from the ACOE Contaminant Biota-Sediment Accumulation Factor Database (Table 4) (USACOE 1999). 
Although the results of the modified equation showed an improved correlation between empirical and theoretical concentrations of contaminants in clams, the majority of $\mathrm{PCB}$ concentrations and PAH concentrations were still underpredicted and overpredicted respectively (Table 4, Figures 5 and 6). This lack of accurate correlation indicates that there are other factors influencing contaminant accumulation in clams.

\subsection{Creation of a New Bioaccumulation Model}

Most existing bioaccumulation models have too many complex variables and are too limited in applicability for managers to use regularly. The one model mentioned in this section that does meet these criteria, the TBP model, does not accurately predict organism accumulation of contaminants from sediment. Therefore, some of the assumptions under which these models function may be incorrect. In order to assist managers in site assessment, a new bioaccumulation model for PAHs and PCBs in Mya arenaria was developed. First, a new mass balance diagram was designed, outlining the relevant environmental compartments for accumulation of nonpolar organic compounds in clams (Figure 7). Second, different model iterations examined the impact of these biological and chemical compartments, including: 1) chemical partitioning into lipid and organic matter, 2) chemical partitioning into organism protein, 3) exposure to contaminants through ingestion of contaminated food particles, and 4) chemical partitioning into the sedimentary soot fraction. 
Figure 4. Map of sample sites for sediment and clam data (McDowell and Shea 1997) (above) and sedimentary soot carbon fractions (Gustafsson and Gschwend 1998) (below).
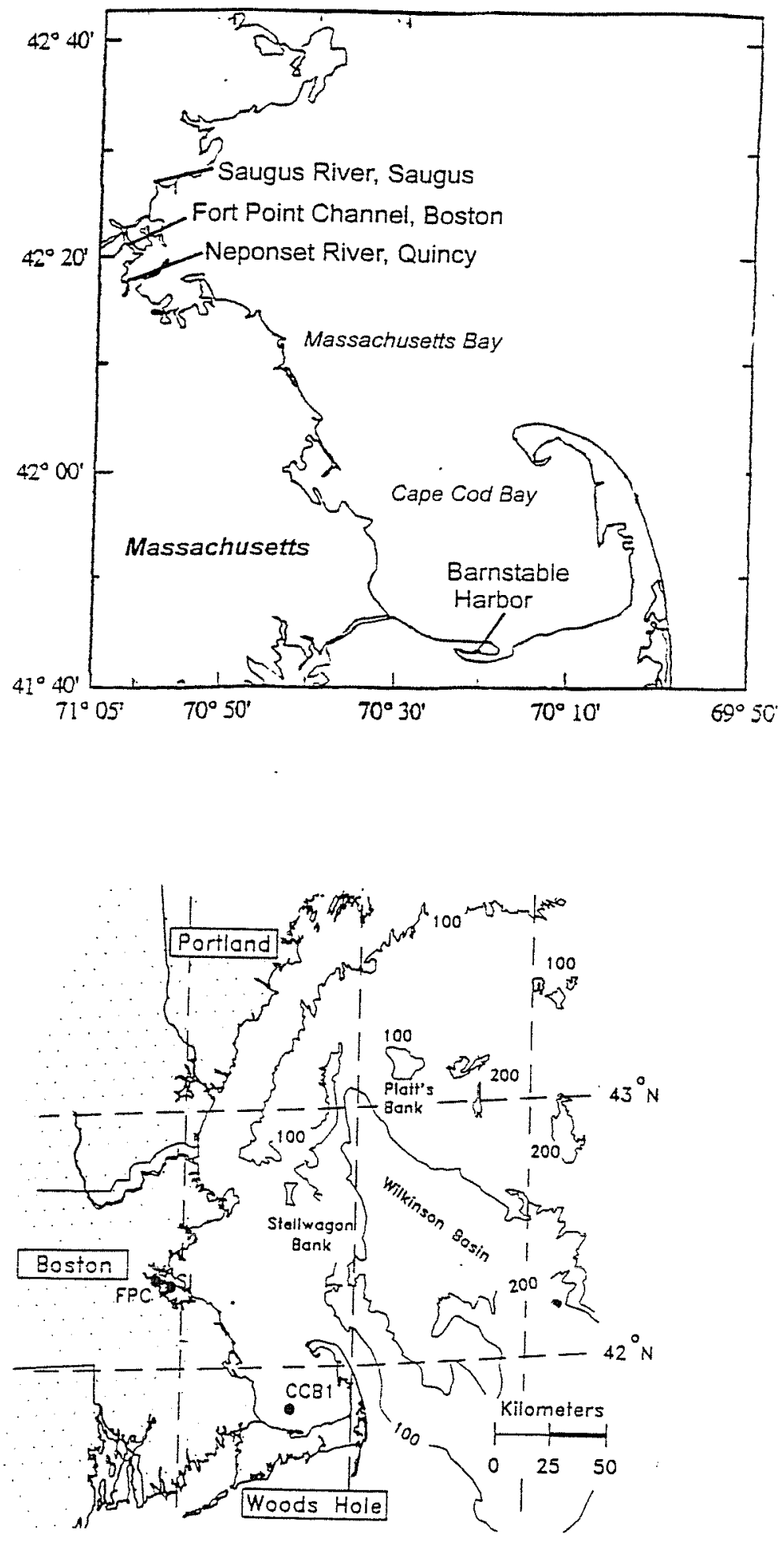


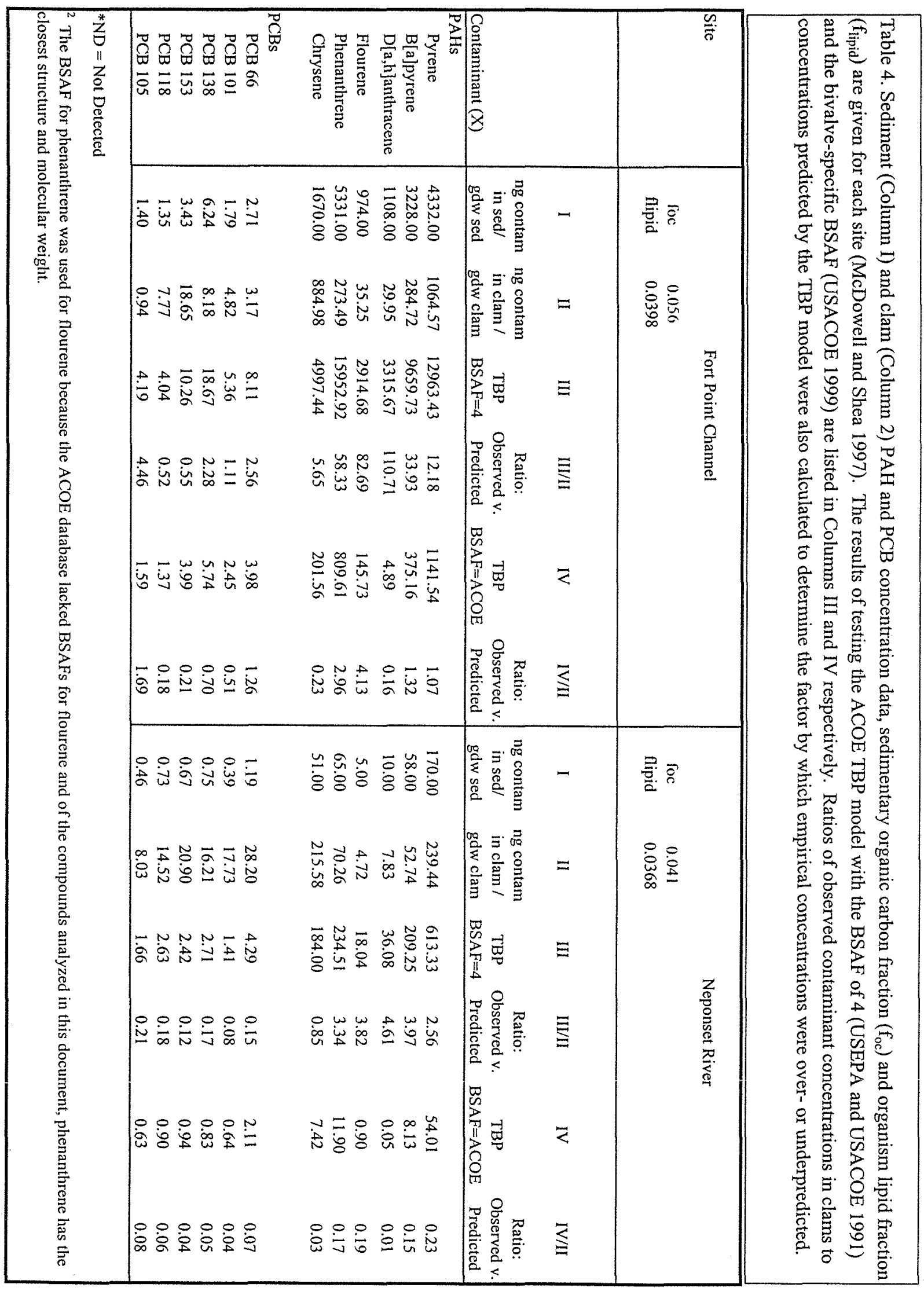




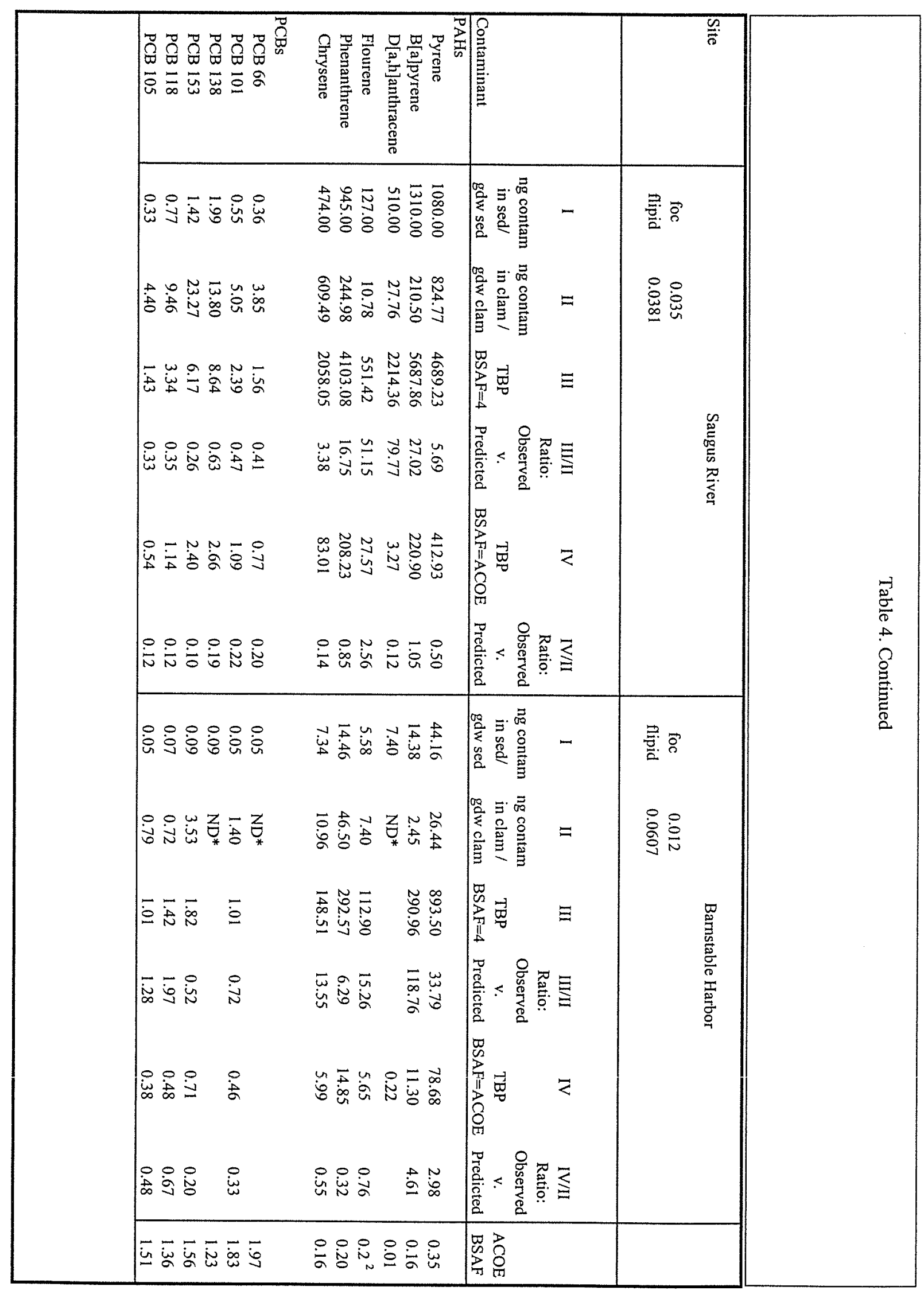




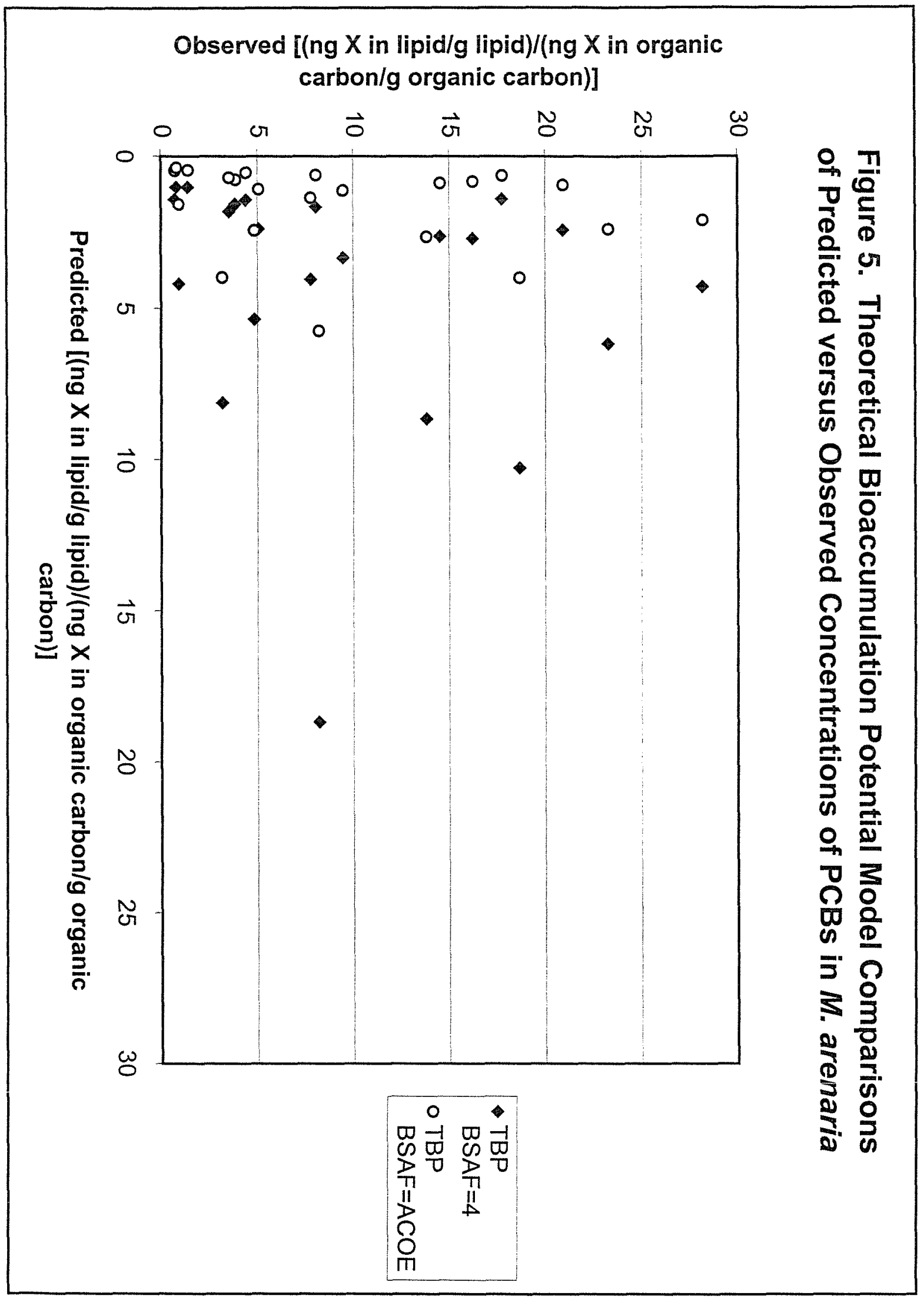




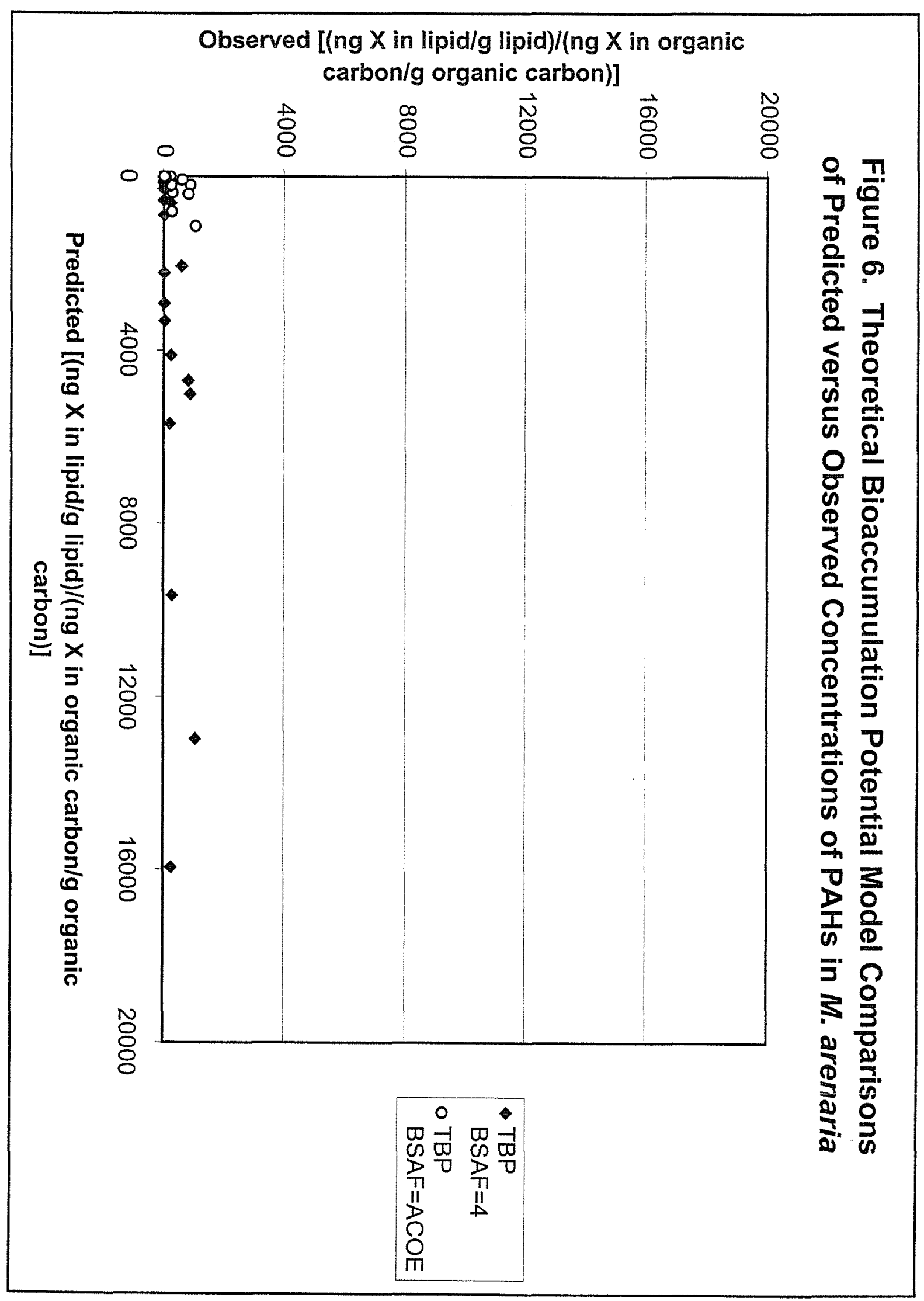


Figure 7. Diagram of the environmental compartments that influence the concentration of nonpolar organic compounds in clams assuming equilibrium. The model is based on references and information as noted in the text.

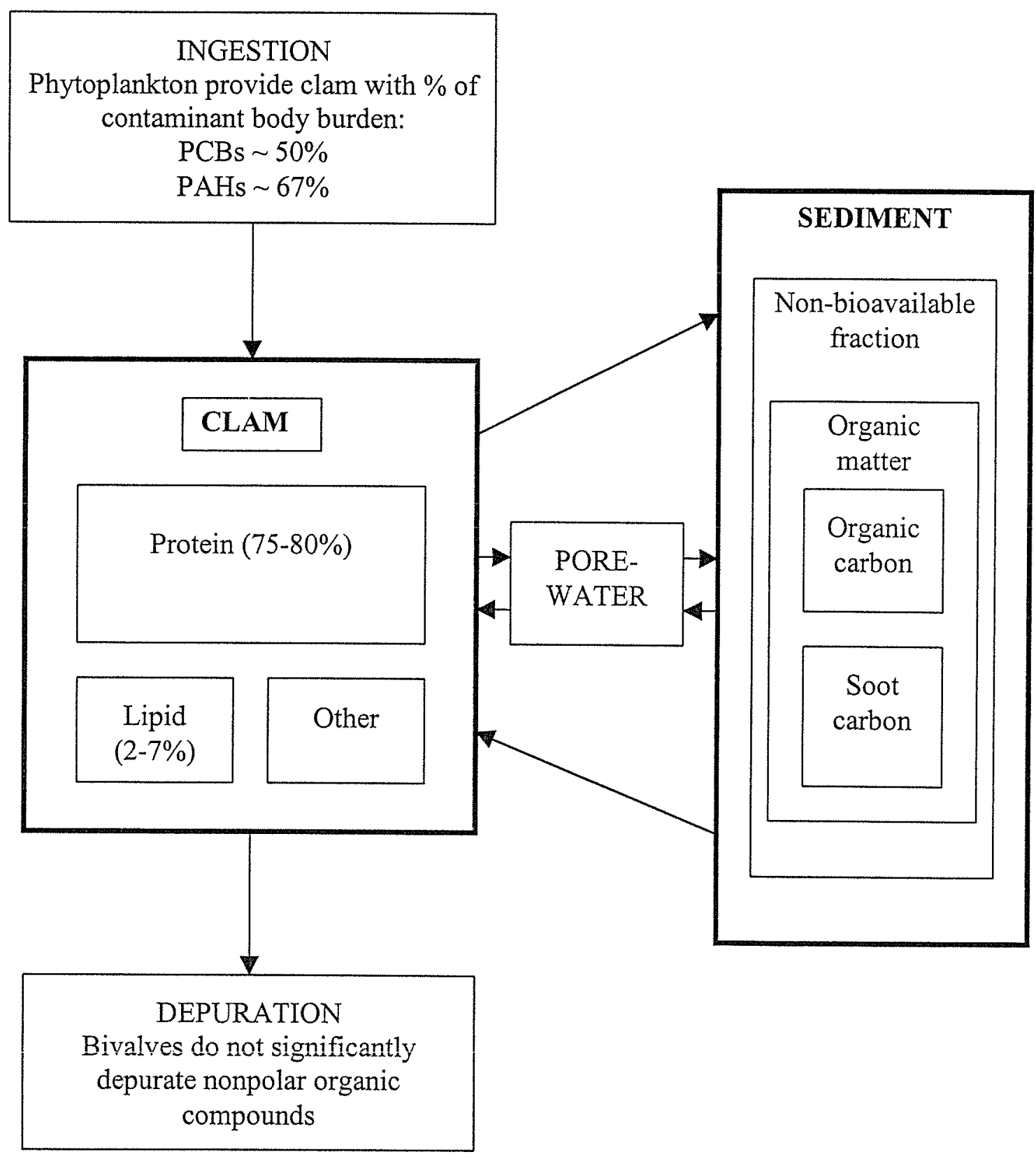




\subsection{Materials and Methods}

Sediment and Mya arenaria contamination data from McDowell and Shea (1997) were used to determine the accuracy of model predictions. In March 1995, they collected both sediment and clam samples from four stations in Massachusetts Bay (Fort Point Channel, (FPC) Neponset River (NR), Saugus River (SR) and Barnstable Harbor (BH)) that were analyzed for a suite of PAH compounds (Figure 4) (McDowell and Shea 1997). Organism lipid fractions $\left(f_{\text {lipid }}\right)$ were also reported (McDowell and Shea 1997) (Table 4).

For this analysis, data used to test the theoretical models were confined to the compounds for which there was corresponding sediment and clam data at each site (McDowell and Shea 1997). Therefore, the compounds reviewed (in order of increasing hydrophobicity) are PAHs flourene, phenanthrene, pyrene, chrysene, benzo[a]pyrene and dibenz[a,h]anthracene, and PCB congeners 66, 101, 105, 118, 137 and 153. Any concentration of contaminant in sediment reported as $<0.10$ [ng contaminant/g sediment] was used in this analysis as half the "detection limit," e.g. 0.05 [ng contaminant/g sediment]. The percent organic carbon in the McDowell and Shea (1997) sediment samples were not published in the report but were obtained directly from D. Shea (Shea, personal communication) (Table 4). The fraction of organic carbon in the sediment was converted to the organic matter fraction by estimating:

$$
f_{o m}=2 * f_{o c} \quad \text { (Schwarzenbach et al. 1993) }
$$

Partition coefficients were used to describe the tendency of a contaminant to partition into one environmental compartment, such as organic matter, versus its tendency to dissolve into water. These coefficients were recorded from various literature sources. Compoundspecific organic matter-water partition coefficients $\left(\mathrm{K}_{\mathrm{om}}\right)$ were not readily available, 
however, and were therefore calculated using a linear relationship between $\mathrm{K}_{\mathrm{om}}$ and the corresponding octanol-water partition coefficients $\left(\mathrm{K}_{\mathrm{ow}}\right)$ (Table 5). For PAHs, using $\mathrm{K}_{\mathrm{ow}} \mathrm{s}$ from CRC (1995):

$$
\begin{array}{ll}
\log \mathrm{K}_{\mathrm{om}}=1.01 \log \mathrm{K}_{\mathrm{ow}}-0.72 \quad & \text { (Schwarzenbach et al. } 1993 \text { using data from } \\
& \text { Karickhoff 1981). }
\end{array}
$$

For PCBs, $\mathrm{K}_{\mathrm{om}}$ values were determined from the following equation using $\mathrm{K}_{\mathrm{ow}}$ values from Hawkes and Connell (1988):

$$
\begin{array}{ll}
\log \mathrm{K}_{\mathrm{om}}=0.88 \log \mathrm{K}_{\mathrm{ow}}-0.27 \quad & \text { (Schwarzenbach et al. } 1993 \text { using data from } \\
& \text { Karickhoff 1981). }
\end{array}
$$




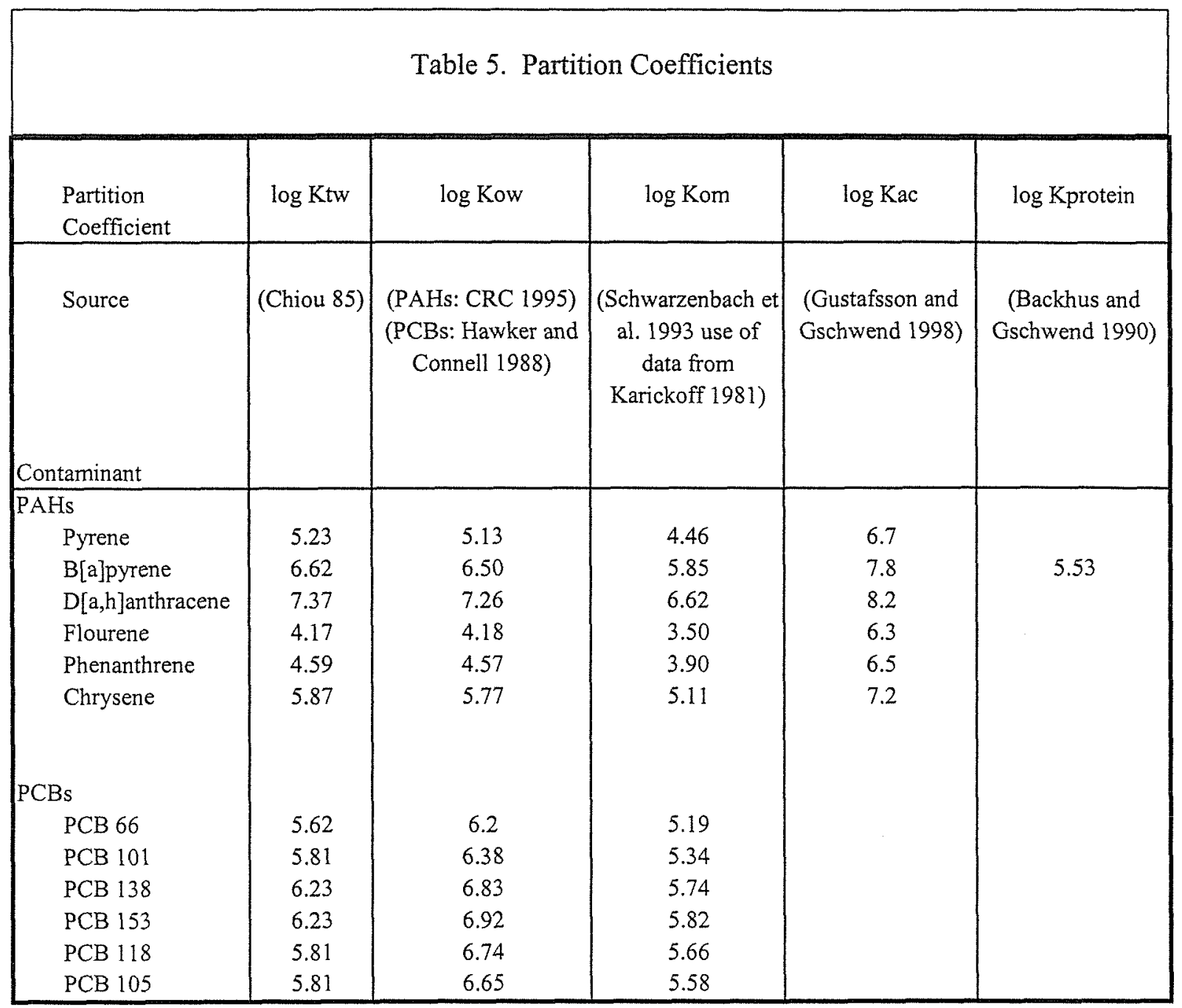




\subsection{Results and Discussion}

\subsection{First Level Model}

In order to design a bioaccumulation model, a base set of empirical and theoretical equations was determined using traditional assumptions. This base model is the framework upon which future iterations of the model were built. For this first level model, the following assumptions were made: 1) sediment and biota are at equilibrium, 2) contaminants partition only into the lipid fraction of the organism, 3) sediment is the only route of contaminant exposure, 4) contaminants partition only into the organic matter fraction of the sediment, and 5) contaminants are not degraded. The equilibrium assumption presumes that the system has reached steady state, i.e. the fugacities of a contaminant in the various environmental phases have had enough time to equilibrate. The bioavailability assumption is supported by research showing that bioavailability can equal one hundred percent (Burton and Scott 1992). The assumption that the amount of contaminant within the system is constant is supported by evidence that while some benthic organisms have the ability to metabolize nonpolar organics, mollusks lack the physiology to convert these compounds into less toxic forms (Anderson 1985, Stegeman 1985). In addition, mollusks do not readily excrete PAH or PCB compounds (Tanacredi and Cardenas 1991).

The first level model uses a chemical partitioning approach to represent PCB and PAH bioaccumulation in $M$. arenaria. Under the above assumptions, partition coefficients were used to describe the amount of chemical that dissolves into one environmental compartment, i.e. organism lipid or sedimentary organic matter, versus the amount that dissolves into one liter of water. As triolein is a substance similar to organism lipid, the triolein-water partition coefficient $\left(\mathrm{K}_{\mathrm{tw}}\right)$ (Chiou 1985) represents the partitioning into organism lipid and the organic matter-water partition coefficient $\left(\mathrm{K}_{\mathrm{om}}\right)$ represents chemical partitioning into sedimentary organic material. 
The theoretical "biological" partition coefficient $\left(\mathrm{K}_{\text {bio-theoretical }}\right)$ relating the concentrations of contaminant in the organism and the sediment is therefore:

$$
\begin{aligned}
\mathrm{K}_{\mathrm{tw}} / \mathrm{K}_{\mathrm{om}} & =\left(\mathrm{C}_{\text {clam }} / \mathrm{f}_{\text {lipid }}\right) /\left(\mathrm{C}_{\text {sed }} / \mathrm{f}_{\mathrm{om}}\right) \\
& =\frac{[(\mathrm{ng} \text { contaminant in clam } / \mathrm{g} \text { clam }) /(\mathrm{g} \text { lipid } / \mathrm{g} \text { clam })]}{[(\mathrm{ng} \text { contaminant in sediment } / \mathrm{g} \text { sediment }) /(\mathrm{g} \text { organic matter } / \mathrm{g} \text { sed })]}
\end{aligned}
$$

where:

$$
\begin{aligned}
& \mathrm{K}_{\mathrm{tw}}=\frac{[\underline{\mathrm{ng} \text { contaminant in triolein } / \mathrm{g} \text { triolein }]}}{[\mathrm{ng} \text { contaminant in water } / \mathrm{L} \text { water }]} \\
& \mathrm{K}_{\mathrm{om}}=\frac{[\mathrm{ng} \text { contaminant in organic matter } / \mathrm{g} \text { organic matter }]}{[\mathrm{ng} \text { contaminant in water } / \mathrm{L} \text { water }]} \\
& \mathrm{C}_{\mathrm{clam}}=[\mathrm{ng} \text { contaminant in clam } / \mathrm{g} \text { clam }] \\
& \mathrm{C}_{\text {sediment }}=[\mathrm{ng} \text { contaminant in sediment } / \mathrm{g} \text { sediment }] \\
& \mathrm{f}_{\text {lipid }}=[\mathrm{g} \text { lipid } / \mathrm{g} \text { clam }] \\
& \mathrm{f}_{\mathrm{om}}=[\mathrm{g} \text { organic matter } / \mathrm{g} \text { sediment }]
\end{aligned}
$$

The same empirical data, described above (Section 8), that was also used to test the TBP model was used to test the first level chemical partitioning model (McDowell and Shea 1997). An empirical biota-water partition coefficient $\left(\mathrm{K}_{\text {bio-empircal }}\right)$ was calculated, normalizing clam concentrations to the lipid fraction and sediment concentrations to the organic matter fraction:

$$
\begin{aligned}
\mathrm{K}_{\text {bio-empirical }} & =\left(\mathrm{C}_{\text {clam }} / \mathrm{f}_{\text {lipid }}\right) /\left(\mathrm{C}_{\mathrm{s}} / \mathrm{f}_{\text {om }}\right) \\
& =\frac{[\mathrm{ng} \text { contaminant in clam } / \mathrm{g} \text { lipid] }}{[\mathrm{ng} \text { contaminant in sediment } / \mathrm{g} \text { organic matter }]}
\end{aligned}
$$

$\mathrm{K}_{\text {tio-theoretical }}$ (predicted) was compared to $\mathrm{K}_{\text {bi-empinical }}$ (observed) for both PAHs and PCBs. The results of this first level model both underpredict the majority of $\mathrm{PCB}$ concentrations in clams by a factor of 3-30 and overpredict most PAHs clam concentrations by at least 


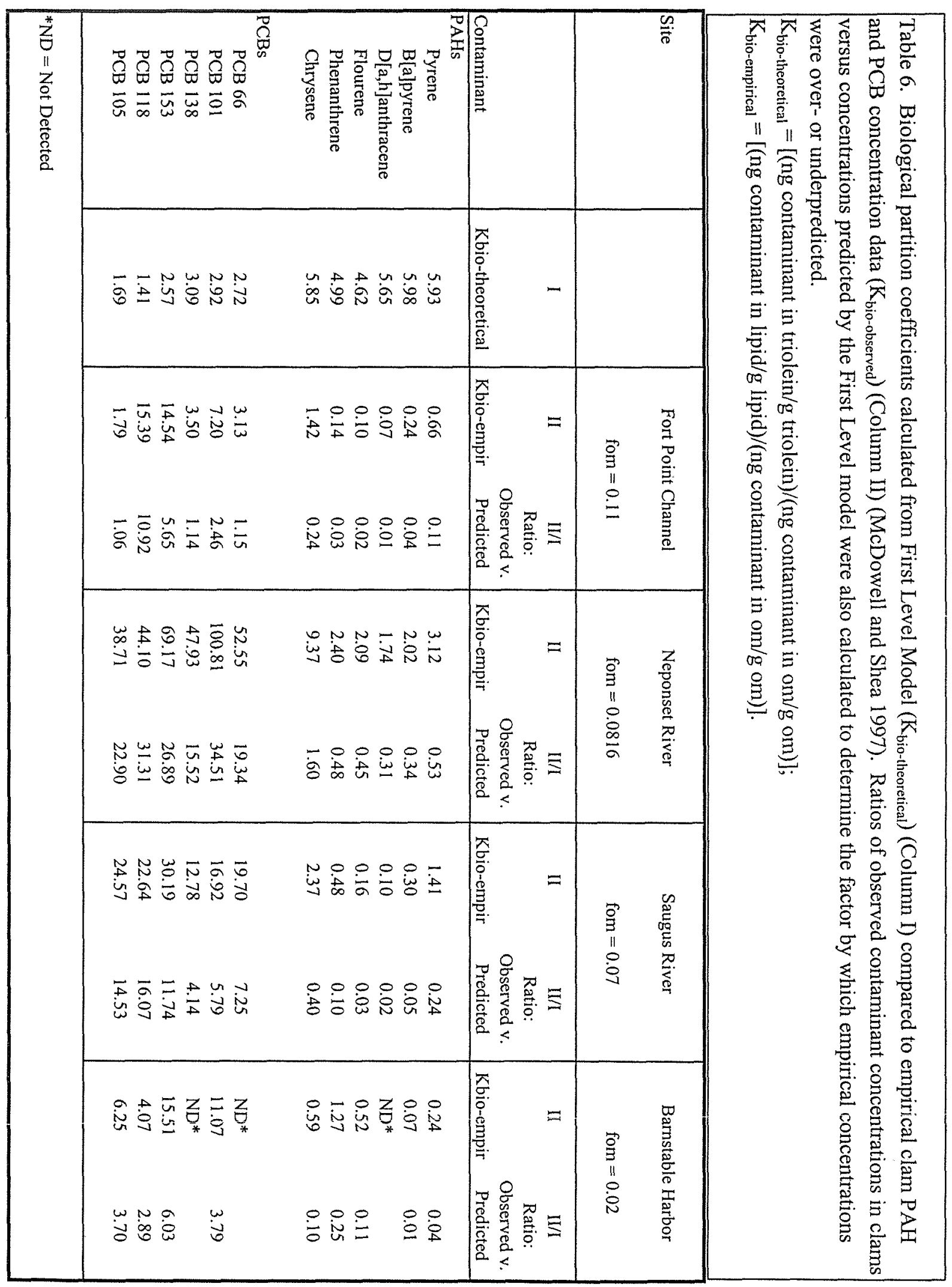


one order of magnitude (Table 6). This indicates that one or more of the original assumptions are incorrect.

\subsection{Second Level Model}

Although hydrophobic chemicals have the highest tendency to partition into the lipid fraction of each environmental compartment, it is possible that a significant amount of contaminant may partition into other materials. Therefore, the assumption that contaminants in clams should be lipid-normalized may be inaccurate. For example, protein is only one order of magnitude less sorptive than lipid, and in the case of $M$. arenaria, it comprises 75-80 percent of the clam body (McDowell, personal communication). Assuming no other material in the clam is sorptive, contaminant partitioning into protein was incorporated in this model iteration. Only one protein-water partition coefficient $\left(\mathrm{K}_{\text {protein }}\right)$ relevant to the contaminants of interest was found in the literature; it is for perylene in bovine serum albumin (Backhus and Gschwend 1990). Because perylene is so close in structure to benzo[a]pyrene (5-ring hydrocarbon molecule), this $\mathrm{K}_{\text {protein }}$ was used to describe the partitioning of benzo[a]pyrene. The same $\mathrm{K}_{\text {protein }}$ was also used for PCB 153 , as the $\log \mathrm{K}_{\mathrm{ow}}$, i.e. the tendency to partition out of water, are roughly the same for benzo[a]pyrene and PCB 153 (Table 5).

Therefore, the amount of contaminant that partitions into the protein and lipid fractions of an individual $M$. arenaria is:

$$
\begin{aligned}
\mathrm{K}_{\text {bio2-theoretical }}= & {\left[\left(\mathrm{K}_{\text {tw }}{ }^{*} f_{\text {lipid }}\right)+\left(\mathrm{K}_{\text {protein }}{ }^{*} \mathrm{f}_{\text {protein }}\right)\right] /\left[\mathrm{K}_{\mathrm{om}}\right] } \\
= & {[\underline{\mathrm{ng} \text { contaminant in clam } / \mathrm{g} \text { clam }}] } \\
& {[\text { ng contaminant in organic matter/g organic matter }] }
\end{aligned}
$$

where:

$$
\begin{aligned}
& \mathrm{K}_{\text {protein }}=\frac{[\text { ng contaminant in protein } / \mathrm{g} \text { protein }]}{[\text { ng contaminant in water } / \mathrm{L} \text { water }]} \\
& \mathrm{f}_{\text {protein }}=[\mathrm{g} \text { protein } / \mathrm{g} \text { clam }]
\end{aligned}
$$


In order to compare model results with empirical data, $\mathrm{K}_{\text {bio2-empirical }}$ was derived using the concentration of contaminant in the entire clam without normalizing to the lipid fraction and the concentration of contaminant in the sediment normalized to organic matter:

$$
\begin{aligned}
\mathrm{K}_{\text {bioz-empirical }} & =\left(\mathrm{C}_{\text {clam }}\right) /\left(\mathrm{C}_{\text {sediment }} / \mathrm{f}_{\text {om }}\right) \\
& =\frac{[(\mathrm{ng} \text { contaminant in clam } / \mathrm{g} \text { clam })]}{[(\mathrm{ng} \text { contaminant in sediment } / \mathrm{g} \text { organic matter })]}
\end{aligned}
$$

$\mathrm{K}_{\text {bio2-theoretical }}$ (predicted) was compared to $\mathrm{K}_{\text {bio2-empirical }}$ (observed). The correlation between empirical and theoretical concentrations in clams for PCB 153 was improved significantly over results from the First Level Model; observed and predicted concentrations are similar at FPC and $\mathrm{BH}$, and are only underpredicted by a factor of approximately 2 for SR and 5 for NR (Table 7). There is too little data to run in-depth statistical analyses, making it difficult to determine whether differences between empirical and theoretical contaminant concentrations are significant. For the purposes of this study, this model is assumed to predict with reasonable accuracy the concentrations of PCBs in M. arenaria. Results for benzo[a]pyrene, however, are still overpredicted by 1-2 orders of magnitude (Table 7). In order to improve the correlation of empirical and theoretical data, another assumption of the model must be tested for inconsistency. 


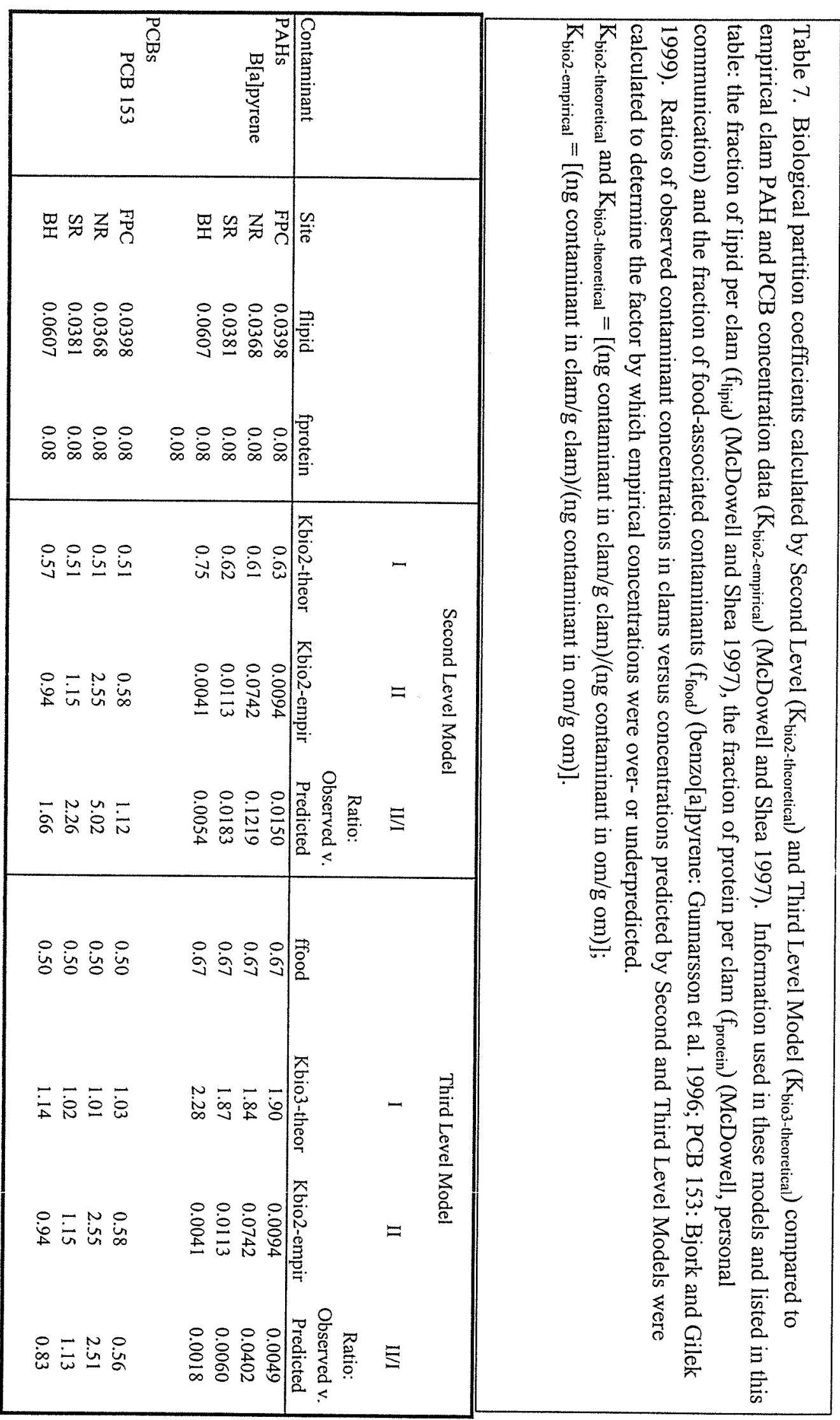




\subsection{Third Level Model}

Because clams are not passive lumps of organic material that simply exist in the sediment but rather are active, living organisms, the assumption that sediment is the only route of exposure to contaminants is inaccurate. Previously developed models of bioaccumulation have shown improved results when a "food" component is added (Thomann et al. 1992). For filter feeders such as $M$. arenaria, a significant amount of contaminant uptake occurs through ingestion of contaminated particles, mainly plankton (McDowell, personal communication). For benzo[a]pyrene, the percent of contamination associated with food intake is approximately 67 percent (Gunnarsson et al. 1996), and for PCB 153, 50 percent of bivalve contamination is food associated (Bjork and Gilek 1999).

Assuming direct contact with sediment and ingestion of contaminated food are the only two exposure routes, total exposure of the clam to contaminants is:

$$
\mathrm{C}_{\text {clam-total }}=\left(\mathrm{x} * \mathrm{C}_{\text {clam-sediment }}\right)+\left(\mathrm{y} * \mathrm{C}_{\text {clam-phytoplankton }}\right)
$$

where:

$\mathrm{x}=$ fraction of contaminants from sediments found in organism

$y=$ fraction of contaminants from food found in organism

Therefore, the Third Level Model is:

$$
\begin{aligned}
\mathrm{K}_{\text {bio3-theoretical }}= & {\left[\left(\left(\mathrm{K}_{\mathrm{tw}} * \mathrm{f}_{\text {lipid }}\right)+\left(\mathrm{K}_{\text {protein }} * \mathrm{f}_{\text {protein }}\right)\right) /\left(\mathrm{K}_{\mathrm{om}}\right)\right] *\left(1 /\left(1-\mathrm{f}_{\text {food }}\right)\right) } \\
= & {[\underline{\text { ng contaminant in clam } / \mathrm{g} \text { clam }]}} \\
& {[\text { ng contaminant in organic matter/g organic matter }] }
\end{aligned}
$$

where:

$f_{\text {food }}=$ percentage of food-associated contaminants $* 100$ 
$\mathrm{K}_{\text {bio3-theoretical }}$ (predicted) was compared to $\mathrm{K}_{\text {bio2-empircal }}$ (observed). Results show an improvement in the correlation of empirical and theoretical concentrations of PCB 153 in M. arenaria (Table 7). Again, there is too little data to run in-depth statistical analyses, but for the purposes of this study, the model predictions and empirical observations are assumed to be equal. This is assumed to be true for all PCB congeners. For benzo[a]pyrene, empirical concentrations are underpredicted by a factor of approximately 24-550 (Table 7). This is assumed to be true for all PAH compounds. One explanation for the wide discrepancy in the PAH results is the existence of some environmental factor that affects PAH molecules but not PCBs.

\subsection{Fourth Level Model}

Because of the inability of the model to predict empirical concentrations of PAHs in $M$. arenaria, another of the original assumptions is presumed to be invalid. This most likely is the assumption that contaminants in sediment only partition into organic matter. Previous work has shown that soot particles may sequester PAH molecules, which may be a factor in reducing the bioavailability of PAHs to bethically-coupled organisms such as M. arenaria (Gustafsson et al. 1997, Gustafsson and Gschwend 1998). In Boston Harbor specifically, only a fraction of the total measured PAH concentration in sediment is available for exchange with other environmental phases (McGroddy et al. 1996, McGroddy and Farrington 1995). Although it is possible that PCB molecules with a planar structure may also be sequestered and rendered un-bioavailable, this is assumed to be insignificant compared to PAHs.

$\mathrm{K}_{\text {bio2-theoretical }}$ was modified to include the partitioning ability of PAHs into soot (activated carbon) versus water $\left(\mathrm{K}_{\mathrm{ac}}\right.$ ) (Gustafsson and Gschwend 1998). The fraction of soot in sediment measured by Gustafsson and Gschwend (1998) were extrapolated from their study sites to the sites of the empirical data from McDowell and Shea (1997) (Figure 4): 
McDowell and Shea (1997)

Site: $\quad$ FPC

NR and SR

$\mathrm{BH}$
Gustafsson and Gschwend (1997)

Fort Point Channel (FPC)

Spectacle Island (SI)

Cape Cod Bay (CCB1)

To calculate the ratio of soot to organic matter, site specific black carbon $(\mathrm{BC}) /$ total organic carbon (TOC) ratios (Gustafsson and Gschwend 1998) were converted to a BC/ total organic matter (TOM) ratio and then to a $\mathrm{BC} /$ Sediment ratio:

$$
\begin{aligned}
& \text { BC } /\left(\text { TOC }^{*} 2\right)=\text { BC/TOM }[\mathrm{g} \text { soot } / \mathrm{g} \text { om }] \quad \text { (Schwarzenbach et al. 1993) } \\
& (\mathrm{BC} / \mathrm{TOM}) * \mathrm{f}_{\text {om }}=\mathrm{f}_{\mathrm{sc}}[\mathrm{g} \text { soot/g sediment }]
\end{aligned}
$$

The total contaminant sorbed to sediment and not bioavailable is:

$$
\left(\mathrm{K}_{\mathrm{om}} * \mathrm{f}_{\mathrm{om}}\right)+\left(\mathrm{K}_{\mathrm{ac}} * \mathrm{f}_{\mathrm{sc}}\right)
$$

where:

$\mathrm{K}_{\mathrm{ac}}=$ [ng contaminant in soot/g soot $]$

[ng contaminant in water/L water]

$\mathrm{f}_{\mathrm{sc}}=[\mathrm{g}$ soot carbon $/ \mathrm{g}$ sediment $]$

Replacing $\mathrm{K}_{\mathrm{om}}$ in the Third Level Model for PAHs with the total contaminant not bioavailable results in the Fourth Level Model calculation of $\mathrm{K}_{\text {bio4-theoretical }}$ :

$$
\begin{aligned}
\mathrm{K}_{\text {bio4-theoretical }}= & {\left.\left[\left(\left(\mathrm{K}_{\mathrm{tw}} * \mathrm{f}_{\text {lipid }}\right)+\left(\mathrm{K}_{\text {protein }} * \mathrm{f}_{\text {protein }}\right)\right) /\left(\left(\mathrm{K}_{\mathrm{om}} * \mathrm{f}_{\mathrm{om}}\right)+\mathrm{K}_{\mathrm{ac}} * \mathrm{f}_{\mathrm{sc}}\right)\right)\right] *\left(1 /\left(1-\mathrm{f}_{\mathrm{food}}\right)\right) } \\
= & {[\underline{\mathrm{ng} \text { contaminant in triolein } / \mathrm{g} \text { triolein }]}} \\
& {[\mathrm{ng} \text { contaminant in organic matter/g organic matter }] }
\end{aligned}
$$


A new empirical partition coefficient was also calculated, eliminating the normalization of sediment contamination concentrations to organic matter used in previous model iterations:

$$
\mathrm{K}_{\text {bio4-empirical }}=\mathrm{C}_{\text {clam }} / \mathrm{C}_{\text {sed }} \quad[\text { ng contaminant } / \mathrm{g} \mathrm{clam}] /[\mathrm{ng} \text { contaminant } / \mathrm{g} \text { sed }]
$$

$\mathrm{K}_{\text {bio4-theoretical }}$ (predicted) was compared to $\mathrm{K}_{\text {bio4-empirical }}$ (observed). The difference between empirical and theoretical concentrations of benzo[a]pyrene in $M$. arenaria are improved by the incorporation of soot partitioning in the model: the correlation for three sites (FPC, NR and SR) is off by a factor of 4-32 (Table 8). This shows that soot does play a role in sequestering $\mathrm{PAH}$ molecules and decreasing their bioavailability to organisms such as $M$. arenaria. The correlation between observed and predicted benzo[a]pyrene concentrations in Barnstable Harbor, however, is off by a factor of approximately 225. See Section 9.6 for possible reasons for this discrepancy. Although incorporation of soot improves the accuracy of model predictions, it still does not outline the complete picture of $\mathrm{PAH}$ bioaccumulation in clams; another mechanism(s) must be involved. 
Table 8. Biological partition coefficients calculated by Fourth Level Model ( $\mathrm{K}_{\text {bio4- }}$ theoretical $)$ compared to empirical clam $\mathrm{PAH}$ concentration data $\left(\mathrm{K}_{\text {bio4-empirical }}\right)$ (McDowell and Shea 1997). The fraction of soot carbon $\left(f_{s c}\right)$ in the sediment is also listed per site (Gustafsson and Gschwend 1997).

$\mathrm{K}_{\text {bio4-theoretical }}=[(\mathrm{ng}$ contaminant in clam $/ \mathrm{g}$ clam $) /(\mathrm{ng}$ contaminant in sediment $/ \mathrm{g}$ sediment)];

$\mathrm{K}_{\text {bio4-empirical }}=[(\mathrm{ng}$ contaminant in clam $/ \mathrm{g}$ clam $) /(\mathrm{ng}$ contaminant in sediment $/ \mathrm{g}$ sediment)].

\begin{tabular}{|l|lc|cccc|}
\hline & & & \multicolumn{3}{|c|}{ Fourth Level Model } \\
& & & & & & \\
& & & & II & II/I \\
& & & & & & Ratio: \\
& & & & & Observed v. \\
Contaminant & Site & fsc & Kbio5-theor & Kbio5-empir & Predicted \\
\hline PAHs & FPC & 0.0072 & 2.49 & 0.09 & 0.0354 \\
B[a]pyrene & NR & 0.0038 & 4.27 & 0.91 & 0.2128 \\
& SR & 0.0033 & 5.03 & 0.16 & 0.0319 \\
& BH & 0.0004 & 38.46 & 0.17 & 0.0044 \\
& & & & & \\
\hline
\end{tabular}




\subsection{Summary of Methods, Models, Assumptions and Results}

Beginning with a chemical equilibrium partitioning approach to contaminant bioaccumulation, traditional assumptions were modeled and tested against empirical data (McDowell and Shea 1997). These commonly used assumptions include contaminant accumulation in organism lipid and sedimentary organic matter, organism exposure to contaminants only through sediment, and one hundred percent contaminant bioavailability. One model iteration was used to determine the accuracy of each of these assumptions. Building on the original model, parameters were added to improve the correlations between predicted and observed concentrations of PCBs and PAHs in $M$. arenaria. Incorporation of contaminant partitioning into organism protein and the exposure of clams to food-associated contaminants into the model reasonably predicted PCB concentrations in $M$. arenaria and improved the accuracy of PAH predictions. For PAHs, although addition of contaminant partitioning into the sedimentary soot fraction of the sediment caused a further improvement in results, predictions remained inaccurate. Therefore, bioaccumulation must still be affected by factors not considered in this analysis. Table 9 provides a complete summary of the methods, results and assumptions of each iteration of the bioaccumulation model.

\subsection{Sources of Uncertainty}

There are a few sources of uncertainty in the above models due to various extrapolations of input data. First, the $\mathrm{K}_{\text {protein }}$ used for benzo[a]pyrene was empirically derived for perylene. Although the two molecules have similar structures and molecular weights, they may partition slightly differently. The same $\mathrm{K}_{\text {protein }}$ was also used for PCB 153; this congener has a $\log \mathrm{K}_{\mathrm{ow}}$ comparable to that of benzo[a]pyrene. The chlorinated PCB compound, however, may not partition into protein exactly the same as the unchlorinated PAH compound. A second source of data uncertainty exists within the fractions used for sedimentary soot carbon. The soot carbon fractions measured in Massachusetts Bay (Gustafsson and Gschwend 1998) were extrapolated to the sites sampled by McDowell and Shea (1997) for sediment and clam contamination data. Neponset River, Saugus 
River and Barnstable Harbor (McDowell and Shea 1997) are all nearshore areas with multiple contaminant inputs from urban sources, yet Spectacle Island and Cape Cod Bay (Gustafsson and Gschwend 1998) are further offshore and not as heavily influenced by on-shore sources of contamination. Therefore, it is possible that the actual sedimentary soot fraction for NR, SR and $\mathrm{BH}$ is higher than that used in this analysis. 
Table 9

Summary of Bioaccumulation Modeling and Testing

\begin{tabular}{|c|c|c|c|c|}
\hline Model & Method & Results & Assumptions & Comments \\
\hline $\begin{array}{l}\text { First } \\
\text { Level } \\
\text { Model }\end{array}$ & $\mathrm{K}_{\mathrm{tw}} / \mathrm{K}_{\mathrm{om}}$ & $\begin{array}{l}\text { PCBs: } \\
\text { Underpredicts } \\
\text { PAHs: } \\
\text { Overpredicts }\end{array}$ & $\begin{array}{l}\text { Sediment, porewater } \\
\text { and biota are at } \\
\text { equilibrium } \\
\text { Contaminants are } \\
100 \% \text { bioavailable } \\
\text { Contaminants are not } \\
\text { degraded } \\
\text { Sediment is the only } \\
\text { route of exposure } \\
\text { Contaminants mainly } \\
\text { accumulate in organism } \\
\text { lipid and sediment } \\
\text { organic matter }\end{array}$ & \\
\hline $\begin{array}{l}\text { Second } \\
\text { Level } \\
\text { Model }\end{array}$ & $\begin{array}{l}{\left[\left(\mathrm{K}_{\mathrm{tw}}{ }^{*} \mathrm{f}_{\text {lipid }}\right)+\right.} \\
\left(\mathrm{K}_{\text {protein }}{ }^{*}\right. \\
\left.\left.\mathrm{f}_{\text {protein }}\right)\right] /\left[\mathrm{K}_{\mathrm{om}}\right]\end{array}$ & $\begin{array}{l}\text { PCBs: Slightly } \\
\text { underpredicts } \\
\text { PAHs: } \\
\text { Improved } \\
\text { accuracy but } \\
\text { still } \\
\text { overpredicts }\end{array}$ & $\begin{array}{l}\text { Sediment, porewater } \\
\text { and biota are at } \\
\text { equilibrium } \\
\text { Contaminants are } \\
100 \% \text { bioavailable } \\
\text { Contaminants are not } \\
\text { degraded } \\
\text { Sediment is the only } \\
\text { route of exposure } \\
\text { Contaminants mainly } \\
\text { accumulate in organism } \\
\text { lipid and protein and } \\
\text { sediment organic } \\
\text { matter }\end{array}$ & $\begin{array}{l}\text { Benzo[a]pyrene and } \\
\text { PCB } 153 \text { have a } \\
\text { tendency to partition } \\
\text { into protein only } \\
\text { slightly less than } \\
\text { into lipid, but the } \\
\text { clam lipid fraction is } \\
2-7 \% \text { and the } \\
\text { protein fraction is } \\
75-80 \% \text {. }\end{array}$ \\
\hline
\end{tabular}


Table 9 Continued

\begin{tabular}{|c|c|c|c|c|}
\hline Model & Method & Results & Assumptions & Comments \\
\hline $\begin{array}{l}\text { Third } \\
\text { Level } \\
\text { Model }\end{array}$ & $\begin{array}{l}{\left[\left(\left(\mathrm{K}_{\mathrm{tw}}{ }^{*} \mathrm{f}_{\text {lipid }}\right)\right.\right.} \\
+\left(\mathrm{K}_{\text {protein }}{ }^{*}\right. \\
\left.\left.\left.\mathrm{f}_{\text {protein }}\right)\right) /\left(\mathrm{K}_{\mathrm{om}}\right)\right] \\
*\left(1 / 1-\mathrm{f}_{\text {food }}\right)\end{array}$ & $\begin{array}{l}\text { PCBs: Predicts } \\
\text { PAHs: } \\
\text { Improved } \\
\text { accuracy but } \\
\text { still } \\
\text { overpredicts }\end{array}$ & $\begin{array}{l}\text { Sediment, porewater } \\
\text { and biota are at } \\
\text { equilibrium } \\
\text { Contaminants are } \\
100 \% \text { bioavailable } \\
\text { Contaminants are not } \\
\text { degraded } \\
\text { Organism is exposed } \\
\text { through sediment and } \\
\text { ingestion of } \\
\text { contaminated particles } \\
\text { Contaminants mainly } \\
\text { accumulate in organism } \\
\text { lipid and sediment } \\
\text { organic matter }\end{array}$ & $\begin{array}{l}\text { Organisms are not } \\
\text { only exposed to } \\
\text { contaminants in } \\
\text { sediment but also to } \\
\text { contaminated food } \\
\text { particles. } \\
\text { Percent of clam } \\
\text { chemical body } \\
\text { burden associated } \\
\text { with ingestion of } \\
\text { food-associated } \\
\text { particles } \\
\text { PCBs 50\% } \\
\text { PAHs 67\% }\end{array}$ \\
\hline $\begin{array}{l}\text { Fourth } \\
\text { Level } \\
\text { Model }\end{array}$ & $\begin{array}{l}{\left[\left(\left(\mathrm{K}_{\mathrm{tw}} * \mathrm{f}_{\text {lipid }}\right)+\right.\right.} \\
\left(\mathrm{K}_{\text {protein }} *\right. \\
\left.\left.\mathrm{f}_{\text {protein }}\right)\right) /\left(\left(\mathrm{K}_{\mathrm{om}}\right.\right. \\
\left.*_{\mathrm{om}}\right)+\left(\mathrm{K}_{\mathrm{sc}} * \mathrm{f}_{\mathrm{Sc}}\right) \\
)]^{*}\left(1 / 1-\mathrm{f}_{\text {food }}\right)\end{array}$ & $\begin{array}{l}\text { PAHs: } \\
\text { Improved } \\
\text { accuracy but } \\
\text { still } \\
\text { overpredicts }\end{array}$ & $\begin{array}{l}\text { Sediment, porewater } \\
\text { and biota are at } \\
\text { equilibrium } \\
\text { Contaminants are not } \\
100 \% \text { bioavailable; } \\
\text { some PAHs are } \\
\text { sequestered by soot } \\
\text { Contaminant is not } \\
\text { degraded } \\
\text { Sediment is the only } \\
\text { route of exposure } \\
\text { Contaminants mainly } \\
\text { accumulate in organism } \\
\text { lipid and sediment } \\
\text { organic matter }\end{array}$ & $\begin{array}{l}\text { Soot particles } \\
\text { sequester PAH } \\
\text { molecules, } \\
\text { rendering them un- } \\
\text { bioavailable to } \\
\text { organisms }\end{array}$ \\
\hline
\end{tabular}




\subsection{Conclusions and Future Recommendations}

Sediment quality remains an issue of constant importance in any marine ecosystem. For urban harbors and ports such as Boston Harbor in Massachusetts Bay, MA, an understanding of the ultimate fate and toxic potential of contaminants in coastal environments is essential. An accurate method for evaluation of sediment contamination is a fundamental component of this process. Inadequacies in scientific techniques as well as a high level of intra- and inter-agency conflicts of interest, however, have prevented universal acceptance of any sediment quality criteria. After a review and analysis of the various methods available to derive $\mathrm{SQC}$, it is recommended that the state of Massachusetts use a combination of the EPA's proposed Equilibrium Partitioning modeling approach along with the more correlative Threshold Effects Level/Probable Effects Level approach. This will give managers a widely applicable and highly reliable method of sediment quality determination that is cost-effective and easy to implement without compromising the protectiveness of the results. Future work should focus on a method for integrating the two and testing the accuracy of the results.

A necessary supplement to SQC is a measure of the bioaccumulation and biomagnification potential of contaminants in the sediment. For hydrophobic chemicals such as PAHs and PCBs, there is a greater risk of toxic effects propagating throughout the marine food web. A model of the bioaccumulation of these two classes of chemicals in the benthically-coupled filter feeder Mya arenaria was developed. By accounting for: 1) contaminant partitioning into organism lipid and protein, 2) contaminant partitioning into sedimentary organic matter, and 3) ingestion of contaminants associated with food particles, concentrations of PCB 153 in $M$. arenaria were accurately predicted. With the incorporation of contaminant partitioning into the sedimentary soot fraction, this model was also the best predictor of benzo[a]pyrene contamination in $M$. arenaria. Results for $\mathrm{PAH}$ compounds, however, were not accurate enough for use. 
There are a few important areas in which future research would be most helpful for bioaccumulation modeling. The protein partition coefficient used in this analysis could be extrapolated to other compounds and the model tested on multiple PCB data sets to assure accuracy. Prediction of PAH concentrations in M. arenaria is more complex, and future studies should focus on determining other model parameters, physical, biological and chemical. One final recommendation is that future data sets be both comprehensive and long-term. Biota are not static entities, they are constantly changing with respect to their biological cycles and in response to environmental conditions. Sampling multiple sites over time will better indicate field conditions and facilitate predictive modeling. 


\section{References}

Anderson, R.S. 1985. Metabolism of a model environmental carcinogen by bivalve mollusks. Mar. Envir. Res. 17:137-146

ATSDR (Agency for Toxic Substances and Disease Registry). 1987. Draft Toxicological Profile for Selected PCBs. ATSDR, US Public Health Service

Backhus, D.A. and P.M. Gschwend. 1990. Flourescent Polycyclic Aromatic Hydrocarbons as Probes for Studying the Impact of Colloids on Pollutant Transport in Groundwater. Envir. Sci. Technol. 24:1214-1223

Baker, J.E., P.D. Capel and S.J. Eisenreich. 1986. Influence of Colloids on SedimentWater Partition Coefficients of Polychlorobiphenyl Congeners in Natural Waters. Envir. Sci. Technol. 20:1136-1143

Barron, M.G. 1990. Bioconcentration, Will water-borne organic chemicals accumulate in aquatic animals? Envir. Sci. Technol. 24(11):1612-1618

Becker, D.S., R.A. Pastorok, R.C. Barrick, P.N. Booth and L.A. Jacobs. 1989. Contaminated Sediments Criteria Report. PTI Environmental Services for the Washington Department of Ecology, Olympia, WA

Bell, H. Personal communication. March 10, 1999. US Environmental Protection Agency Headquarters, Washington, DC

Bergen, B.J., W.G. Nelson and R.J. Pruell. 1993. Partitioning of polychlorinated biphenyl congeners in the seawater of New Bedford Harbor, Massachusetts. Envir. Sci. Technol. 27:938-942

Berry, W. Personal communication. March 12, 1999. US Environmental Protection Agency Environmental Effects Research Laboratory, Narragansett, RI

Bjork, M. and M. Gilek. 1999. Efficiencies of Polychlorinated Biphenyl Assimilation from Water and Algal Food by the Blue Mussel (Mytilus edulis). Envir. Toxicol. Chem. 18(4):765-771

Boese, B.L., H. Lee III, D.T. Specht, J. Pelletier and R. Randall. 1996. Evaluation of PCB and Hexachlorobenzene Biota-Sediment Accumulation Factors Based on Ingested Sediment in a Deposit-Feeding Clam. Envir. Toxicol. Chem. 15(9):15841589 
Broderius, S.J. 1991. Modeling the Joint Toxicity of Xenobiotics to Aquatic Organisms: Basic Concepts and Approaches. Aquatic Toxicology and Risk Assessment: Fourteenth Volume, ASTM STP 1124, Eds. M.A. Mayes and M.G. Barron, American Society for Testing and Materials, Philadelphia, pp. 101-127

Broderius, S.J., M.D. Kahl and M.D. Hoglund. 1995. Use of Joint Toxic Response to Define the Primary Mode of Toxic Action for Diverse Industrial Organic Chemicals. Envir. Toxicol. Chem. 14(9):1591-1605

Burgess, R. Personal communication. March 10, 1999. US Environmental Protection Agency Environmental Effects Research Laboratory, Narragansett, RI

Burgess, R.M and R.A. McKinney. 1999. Importance of interstitial, overlying water and whole sediment exposures to bioaccumulation by marine bivalves. Envir. Pollut. 104:373-382

Burton, G.A., Jr. and K.J. Scott. 1992. Sediment Toxicity Evaluations-Their Niche in Ecological Assessments. Envir. Sci. Technol. 26(11):2068-2075

Chan, I., J. Chan, R. Tsang and T. Chung. 1998. The Environmental Aspects of Polychlorinated Biphenyls (PCBs)

Chapman, P.M. 1989. Current Approaches to Developing Sediment Quality Criteria. Envir. Toxicol. Chem. 8:589-599

Chiou, C.T. 1985. Partition Coefficients of Organic Compounds in Lipid-Water Systems and Correlations with Fish Bioconcentration Factors. Envir. Sci. Technol. 19(1):57-62

COPA (The Coalition Opposed to PCB Ash in Monroe County, Indiana). 1998. Who's Who: PCBs. An Extract from EPA document EPA/540/s-93/506

CRC. 1995. The CRC Handbook of Chemistry and Physics. 1995-1996 $76^{\text {th }}$ Edition. Ed. D.R. Lide. CRC Press, New York

DiToro, D.M., C.S. Zarba, D.J. Hansen, W.J. Berry, R.C. Swartz, C.E. Cowan, S.P. Pavlou, H.E. Allen, N.A. Thomas and P.R. Paquin. 1991. Technical Basis for Establishing Sediment Quality Criteria for Nonionic Organic Chemicals Using Equilibrium Partitioning. Envir. Toxicol. Chem. 10:1541-1583

Ghirelli, R.P., F.H. Palmer, T.L. Spielman, M. Jung, R.L. Severeid, G.W. Bowes and D.B. Cohen. 1983. Polychlorinated Biphenyls. California State Water Resources Control Board. Special Projects Report No. 83-1sp 
Gunnarsson, J.S., M.T. Schaanning, K. Hylland, M. Skold, D.O. Eriksen, J.A. Berge and J. Skei. 1996. Interactions between Eutrophication and Contaminants. IIII. Mobilization and Bioaccumulation of Benzo(a)pyrene from Marine Sediments. Mar. Pollut. Bull. 33(1-6):80-89

Gustafsson, O. and P.M. Gschwend. 1998. The flux of black carbon to surface sediments on the New England continental shelf. Geochim. Cosmochim. Acta 62(3):465-472

Hardin, G. 1968. The Tragedy of the Commons. Science 162:1243-1248

Harkey, G.A., P.F. Landrum and S.J. Klaine. 1994. Comparison of Whole-Sediment, Elutriate and Pore-Water Exposures for Use in Assessing Sediment-Associated Organic Contaminants in Bioassays. Envir. Toxicol. Chem. 13(8)1315-1329

Hawker, D.W. and D.W. Connell. 1988. Octanol-Water Partition Coefficients of Polychlorinated Biphenyl Congeners. Envir. Sci. Technol. 22:382-387

Hemond, H.F. and E.J. Fechner. 1994. Chemical Fate and Transport in the Environment. Academic Press, Boston

Hull, R.N. and G.W. Suter II. 1994. Toxicological Benchmarks for Screening Contaminants for Potential Concerns for Effects on Sediment-Associated Biota: 1994 Revision. US Department of Energy DE-AC05-84OR21400. June

IJC (International Joint Commission). 1988. Procedures for the assessment of contaminated sediment problems in the Great Lakes. A report prepared by the Sediment Subcommittee and its Assessment Work Group for the IJC, Great Lakes Regional Office

Karickoff, S.W. 1984. Organic Pollutant Sorption in Aquatic Systems. J. Hydraulic Eng. 110(6):707-735

Karickoff, S.W. 1981. Semi-empirical estimation of sorption of hydrophobic pollutants on natural sediments and soils. Chemosphere 10:833-846

Landrum, P.F. 1989. Bioavailability and Toxicokinetics of Polycyclic Aromatic Hydrocarbons Sorbed to Sediment for the Amphipod Pontoporeia hoyi. Envir. Sci. Technol. 23:588-595

Lee, G.F. and R.A. Jones. 1992. Sediment Quality Criteria Development: Technical Difficulties with Current Approaches and Suggested Alternatives. G. Fred Lee and Associates. El Macero, CA 
Long, E.R., D.D. MacDonald, S.L. Smith and F.D. Calder. 1995. Incidence of Adverse Biological Effects Within Ranges of Chemical Concentrations in Marine and Estuarine Sediments. Envir. Mngmt. 19(1):81-97

Long, E.R. and L.G. Morgan. 1990. The potential for biological effects of sedimentsorbed contaminants tested in the National Status and Trends Program. NOAA Technical Memorandum. NOS OMA 52. US National Oceanic and Atmospheric Administration, Seattle, WA

MacDonald, D.D., R.S. Carr, F.D. Calder, E.R. Long and C.G. Ingersoll. 1996. Development and evaluation of sediment quality guidelines for Florida coastal waters. Ecotox. 5:253-278

MacDonald, D.D., S.L. Smith, M.P. Wong and P. Mudroch. 1992. The Development of Canadian Marine Environmental Quality Guidelines. Environment Canada, Ottawa, Ontario

Maruya, K.A., R.W. Risebrough and A.J. Horne. 1997. The Bioaccumulation of Polynuclear Aromatic Hydrocarbons by Benthic Invertebrates in an Intertidal Marsh. Envir. Toxicol. Chem. 16(6):1087-1097

McDowell, J.E. Personal communication. April 28, 1999. Woods Hole Oceanographic Institution, Woods Hole, MA

McDowell, J.E. and D. Shea. 1997. Population Processes of Mya arenaria from Contaminated Habitats in Massachusetts Bays. Report to the Massachusetts Bays Program. MBP-97-01

McGroddy, S.E. and J.W. Farrington. 1995. Sediment Porewater Partitioning of Polycyclic Aromatic Hydrocarbons in Three Cores from Boston Harbor, Massachusetts. Envir. Sci. Technol. 29:1542-1550

McGroddy, S.E., J.W. Farrington and P.M. Gschwend. 1996. Comparison of the in Situ and Desorption Sediment-Water Partitioning of Polycyclic Aromatic Hydrocarbons and Polychlorinated Biphenyls. Envir. Sci. Technol. 30:172-177

Menon, N.N. and N.R. Menon. 1999. Uptake of polycyclic aromatic hydrocarbons from suspended oil borne sediments by the marine bivalve Sunetts scripta. Aq. Toxicol. 45:63-69

Moreno, M.D., K.R. Cooper, R.P. Brown and P. Georgopoulos. 1992. A Physiologically Based Pharmacokinetic Model for Mya arenaria. Mar. Envir. Res. 34:321-325 
MWRA (Massachusetts Water Resources Authority). 1997. The State of Boston Harbor 1996 Questions and Answers about the New Outfall. Massachusetts Water Resources Authority Technical Report No. 97-5

NOAA (National Oceanic and Atmospheric Administration). 1999. NOAA's National Status and Trends Program Sediment Quality Guidelines. (http://seaserver.nos.noaa.gov/projects/nsandt/sedimentquality.html)

NOAA. 1985. Boston Harbor and Massachusetts Bay: Issues, Resources, Status and Management. Proceedings of a Seminar Held June 13, 1985. Washington DC. NOAA Estuary-of-the-Month Seminar Series.

NRC (National Research Council). 1989. Contaminated Marine Sediments - Assessment and Remediation. Report of the Committee on Contaminated Marine Sediments, Marine Board, Commission on Engineering and Technical Systems. Washington, DC

Persaud, D., R. Jaagumagi and A. Hayton. 1992. Guidelines for the Protection and Management of Aquatic Sediment Quality in Ontario. Draft. Water Resources Branch, Ontario Ministry of the Environment. Toronto, Ontario

Salomons, W., N.M. De Rooji, H. Kerdijk and J. Bril. 1987. Sediment as a source for contaminants? Hydrobiologia 149:13-30

Scott, P.K. and K.R. Trowbridge. 1995. Screening-Level Versus Refined Modeling Approaches to Estimating PCB Concentrations in Aquatic Food Webs: A Case Study of Lake Ontario. Environmental Toxicology and Risk Assessment - Third Volume ASTM STP 1218. Eds. J.S. Hughes, G.R. Biddinger and E. Mones. ASTM, Philadelphia, PA. pp. 111-132

Schwarzenbach, R.P., P.M. Gschwend and D.M. Imboden. 1993. Environmental Organic Chemistry. John Wiley \& Sons, Inc. New York

Shaw, G.R. and D.W. Connell. 1984. Physicochemical Properties Controlling Polychlorinated Biphenyl (PCB) Concentrations in Aquatic Organisms. Envir. Sci. Technol. 18:18-23

Shea, D. Personal communication. April 20, 1999. North Carolina State University, Raleigh, NC

Shea, D. 1988. Development of National Sediment Quality Criteria. Envir. Sci. Technol. 22(11):1257-1261 
Stange, K. and D.L. Swackhammer. 1994. Factors Affecting Phytoplankton SpeciesSpecific Differences in Accumulation of 40 Polychlorinated Biphenyls (PCBs). Envir. Toxicol. Chem. 13(11):1849-1860

Stegeman, J.J. 1985. Benzo(a)pyrene oxidation and microsomal enzyme activity in the mussel (Mytilus edulis) and other bivalve mollusc species from the western North Atlantic. Mar. Biol. 89:21-29

Swartz, R.C. 1999. Consensus Sediment Quality Guidelines for Polycyclic Aromatic Hydrocarbon Mixtures. Envir. Toxicol. Chem. 18(4):780-787

Tanacredi, J.T. and R.R. Cardenas. 1991. Biodepuration of Polynuclear Aromatic Hydrocarbons from a Bivalve Mollusc, Mercenaria mercenaria L. Envir. Sci. Technol. 25:1453-1461

Thomann, R.V. 1989. Bioaccumulation Model of Organic Chemical Distribution in Aquatic Food Chains. Envir. Sci. Technol. 23:699-707

Thomann, R.V., J.P. Connolly and T.F. Parkerton. 1992. An Equilibrium Model of Organic Chemical Accumulation in Aquatic Food Webs with Sediment Interaction. Envir. Toxicol. Chem. 11:615-629

Tomey, D. Personal communication. March 11, 1999. US Environmental Protection Agency Region I, Boston, MA

Tracey, G.A. and D.J. Hansen. 1996. Use of Biota-Sediment Accumulation Factors to Assess the Similarity of Nonionic Organic Chemical Exposures to Benthically Coupled Organisms of Differing Trophic Modes. Arch. Envir. Contam. Toxicol. $30: 467-475$

USACOE (US Army Corps of Engineers). 1999. Biota Sediment Accumulation Factor (BSAF) Database. www.wes.army.mil/el/t2dbase.html

USEPA (US Environmental Protection Agency). Draft. Technical Basis for Deriving Sediment Guidelines for PAH Mixtures for the Protection of Benthic Organisms by Using Equilibrium Partitioning. Office of Science and Technology and Office of Research and Development, Washington DC

USEPA. 1998a. Contaminated Sediment Strategy. Office of Water, Washington, DC.

USEPA. 1998b. National Conference on Management and Treatment of Contaminated Sediment Proceedings, Cincinnati, OH. May 13-14, 1997. Office of Research and Development, Washington DC 
USEPA. 1993a. Technical Basis for Deriving Sediment Quality Criteria for Nonionic Organic Contaminants for the Protection of Benthic Organisms by Using Equilibrium Partitioning. EPA-822-R-93-011. Washington, DC. September

USEPA. 1993b. Sediment Quality Criteria for the Protection of Benthic Organisms: Acenapthene. EPA-822-R-93-013. Washington, DC. September

USEPA. 1992. National Study of Chemical Residues in Fish. Volume II. Office of Science and Technology Standards and Applied Science Division. Washington, DC. September

USEPA. 1990. Managing Contaminated Sediments, EPA Decision-Making Process. USEPA Sediment Oversight Technical Committee, Washington DC. EPA 506/6$90 / 002$

USEPA. 1989. Evaluation of the Apparent Effects Threshold (AET) Approach for Assessing Sediment Quality. Report of the Sediment Criteria Subcommittee. Science Advisory Board. Washington, DC. SAB-EETFC-89-027

USEPA. 1987. Regulatory Applications of Sediment Criteria. Washington, DC.

USEPA and USACOE. 1991. Evaluation of Dredged Material Proposed for Ocean Disposal Testing Manual. Office of Water, US Environmental Protection Agency and Department of the Army, US Army Corps of Engineers. EPA 503/S-91/001

USGS (United States Geological Survey). 1997. Summary of Discussions During the Interactive Short Course on "Use of Sediment Quality Guidelines in the Assessment and Management of Contaminated Sediments." Presented before the 18th Annual Meeting of the Society of Environmental Toxicology and Chemistry (SETAC) in San Francisco, CA. November

Versar. 1980. Production and Use of PCB 1248 and 1254. Prepared by Versar, Inc. for the US Environmental Protection Agency, Office of Toxic Substances, under contract 68-01-6251, Task 2

Versar. 1976. PCBs in the United States: Industrial Use and Environmental Distribution. Prepared by Versar, Inc. for the US Environmental Protection Agency under contract 68-01-3259, Task 1

WADEC (Washington State Department of Ecology). 1991. Sediment Management Standards. Chapter 173-204 WAC. April. 


\section{Appendix A}

\section{A.O Nonpolar Organic Chemicals: PAHs and PCBs}

Polycyclic aromatic hydrocarbons (PAHs) and polychlorinated biphenyls (PCBs), both classes of nonionic, nonpolar organic compounds, are ubiquitous in the environment and can pose a threat to the success of biological systems.

\section{A.1 PCBs}

\section{Production and Use}

PCB production in the United States began in the late 1920s. Original uses include:

plasticizer in plastic and rubber products, lubricant in hydraulic and vacuum fluids, ink carrier and solvent in manufacturing processes for carbon paper, sealer for gaskets and furnaces and in electrical applications (ATSDR 1987, Ghirelli et al. 1983, Versar 1980, Versar 1976), but by 1974, PCBs were primarily used in dielectric fluid in capacitors and transformers (USEPA 1992). Production continued until 1977, when increasing evidence of the adverse effects of PCBs on human health caused the EPA to ban the productionbased discharge of PCBs. Over the next few years, distribution and use of PCBs were gradually restricted, until in 1985, the use of PCBs was almost completely phased out (USEPA 1992). Decades of PCB use and disposal, however, have caused environmental contamination mainly from industrial discharges, disposal of PCB wastes to municipal sewage treatment plants, landfills and equipment dumps and transport of incompletely incinerated PCBs.

\section{Chemical Characteristics}

PCBs are a group of 209 congeners, each with a different chlorine-dependent molecular composition. Commercial products are usually a mixture of multiple congeners. The fate 
and transport of PCBs and their behavior in surface water and sediment dictates their availability to organisms, which is driven by degree of chlorination and relative insolubility. PCBs are nonionic, nonpolar organic chemicals; molecules have a high tendency to partition out of water and sorb strongly to organic as well as other types of particulate matter (log $\mathrm{K}_{\mathrm{OW}}=4.0-8.5$ for differing congeners) (Scott and Trowbridge 1995). Increasing the number of chlorines per molecule decreases both congener solubility in water and degradation potential and increases sorption potential. Hydrophobicity also gives PCBs a high ability to bioaccumulate in the lipids and tissues of biota.

In general, PCBs are "chemically inert, thermally stable, resistant to hydrolysis by water, alkali and acids, [and] resistan[t] to heat" (Chan et al. 1998). They are also good electrical insulators because of high heat resistance, low flammability and a high dielectric constant (COPA 1998). While degradation is possible, volatilization and hydrolization rarely occur at significant rates, and dechlorination is a time-intensive process (Scott and Trowbridge 1995).

\section{A.2 PAHs}

\section{Production and Use}

Polycyclic aromatic hydrocarbons are formed during the incomplete combustion of organic materials such as coal, oil and gas, garbage and tobacco. In the environment, PAHs are found most often as complex mixtures. They do occur naturally in air, water and soil/sediment but are most often anthropogenically produced. While there is no known direct use of most PAHs, a few are used in medicines as well as in dye, plastic and pesticide production (USEPA 1998b). Others are found in compounds such as coal tar

(used in aluminum reducing processes and in roofing and surface coating) and creosote (used as a preservative agent for railroad ties, marine pilings and telephone poles) (USEPA 1998b). Some pure PAHs are produced commercially for research purposes, but there are few firms in the United States who specialize in PAH production. 


\section{Chemical Characteristics}

There are over a hundred different nonpolar, nonionic PAH compounds. While many of these compounds exist in sediment, only between 13 and $23 \mathrm{PAH}$ compounds are commonly measured in concentration analyses. It is unclear exactly how many PAH compounds need to be measured for acceptable accuracy. As pure chemicals, PAHs most often exist as colorless, white, or pale yellow-green needles, plates, crystals, leaflets or prisms. Stable planar hydrocarbons mainly formed by fused benzene rings, each PAH compound has a different number and configuration of rings. Because they are composed only of carbon and hydrogen, PAHs are relatively insoluble in water, solubility decreasing with increased molecular surface area and increased molecular weight (Schwarzenbach et al. 1993). They have a high hydrophobicity (log Kow $=3.3-7$ (CRC 1995)) causing them to sorb strongly to organic matter and giving them the potential to bioaccumulate. While degradation and chemical alteration of some PAH compounds does occur (e.g. through photooxidation or biological transformation (Burgess, personal communication)), residence times can be from months to years (USEPA 1998b).

\section{A.3 PCBs and PAHs}

\section{Bioavailability}

Recent research shows that soot particles sequester PAH molecules and therefore decrease PAH bioavailability (McGroddy et al. 1996, McGroddy and Farrington 1995). While this issue is too recent to be included in the experimental research for the forthcoming EPA SQC document on PAH mixtures (USEPA Draft), it will be addressed in the discussion (Burgess, personal communication). If soot is a factor in reducing bioavailability, the EqP values will be too conservative. Photo-enhanced toxicity is another aspect of PAH bioavailability that will be addressed only in the document's discussion. Photo-enhanced toxicity occurs because the conjugate structures of PAH molecules can absorb UV radiation (Burgess, personal communication, Schwarzenbach 
et al. 1993). Although this rarely affects PAHs in sediment, it may be important for water column PAHs.

\section{Bioaccumulation}

PCBs and PAHs are known to bioaccumulate through both intake by individual organisms from the environment and biomagnification through the food web. Possible exposure routes of an organism to these nonpolar organic compounds include dermal exposure, ingestion of contaminated sediment, water and food, and inhalation of PCB- or PAH-laden air. The higher an organism in the food web, the more chemical it will accumulate. Because they are soluble in lipids, PCBs and PAHs accumulate in the fatty tissue of biota and are not readily excreted. Specifically for benthic organisms, bioaccumulation is influenced by sediment and porewater characteristics and by organism toxicokinetics. Due to various bioavailability issues, e.g. PAH sequestration in soot particles, less contaminants may be available for uptake to the organism through porewater. In the case of bivalves, however, a decrease in bioavailability of sedimentassociated contaminants may not indicate a decrease in potential toxicity; filter feeders uptake contaminants through both porewater and ingestion of contaminated plankton and colloids from overlying water.

\section{Toxicity}

PCBs and PAHs can be either acutely or chronically toxic to organisms. Acute exposure is usually lethal, while chronic exposure can lead to disrupted hormone balances, reproductive failures, birth defects, skin lesions or carcinomas (USEPA 1998b, COPA 1998). Metabolic processes may also be affected, and immunosuppressive effects may be evident (USEPA 1998b, USEPA 1992). PAHs can also induce narcosis in an organism (Broderius 1995, USEPA 1993a). Toxicity increases with increasing $\mathrm{K}_{\mathrm{ow}}$ because more of the chemical partitions out of the water and into organic matter (e.g. the organism lipid). Toxicity can also vary with the relative concentrations of each congener in the PCB mixture or with the relative abundance of specific PAHs compounds, as some compounds are more toxic than others. Structure-activity research for PAHs also shows 
that the effects of various PAH compounds can be additive (Broderius 1995, USEPA 1993a). 